\title{
Exploring Influences on Parent Support for Child Physical Activity in West Virginia
}

\author{
Jill A. Nolan \\ West Virginia University
}

Follow this and additional works at: https://researchrepository.wvu.edu/etd

\section{Recommended Citation}

Nolan, Jill A., "Exploring Influences on Parent Support for Child Physical Activity in West Virginia" (2011). Graduate Theses, Dissertations, and Problem Reports. 3407.

https://researchrepository.wvu.edu/etd/3407

This Dissertation is protected by copyright and/or related rights. It has been brought to you by the The Research Repository @ WVU with permission from the rights-holder(s). You are free to use this Dissertation in any way that is permitted by the copyright and related rights legislation that applies to your use. For other uses you must obtain permission from the rights-holder(s) directly, unless additional rights are indicated by a Creative Commons license in the record and/ or on the work itself. This Dissertation has been accepted for inclusion in WVU Graduate Theses, Dissertations, and Problem Reports collection by an authorized administrator of The Research Repository @ WVU.

For more information, please contact researchrepository@mail.wvu.edu. 


\title{
Exploring Influences on Parent Support for
} Child Physical Activity in West Virginia

\section{Jill A. Nolan}

Dissertation submitted to the

School of Medicine at West Virginia University in partial fulfillment of the requirements for the degree of

Doctor of Philosophy in

Public Health Sciences

\author{
Geri Dino, PhD, Chair \\ Lesley Cottrell, PhD \\ John Giroir \\ Anoop Shankar, MD, PhD \\ Nancy O'Hara Tompkins, PhD \\ Keith Zullig, PhD
}

Department of Community Medicine

Morgantown, West Virginia

2011

Keywords: physical activity, gender, parent support

Copyright 2011 Jill A. Nolan 


\title{
ABSTRACT \\ Exploring Influences on Parent Support for Child Physical Activity in West Virginia
}

\begin{abstract}
Jill A. Nolan
Physical activity enhances child health. On average, boys are more active than girls. The causes of this disparity are not fully known, but are likely due to factors at multiple levels including individual, interpersonal, organizational, community, and policy. Further, gender stereotypes that associate males with sports and physical activity behavior may also influence child physical activity. What is known is that girls benefit from physical activity just as boys do, and that parental support for boys' physical activity is generally higher than is parental support for girls. Additionally, parental supportive behavior for childhood physical activity is positively associated with increased child physical activity

This project explored the influence of factors at three levels of the Social Ecological Model on parental support for physical activity in West Virginia children. Specifically, we examined the influence of individual parent health behavior and demographic characteristics (individual level), family composition and child gender (interpersonal level), and rurality (community level) on parental supportive behavior. The project utilized secondary data analysis of surveys collected through the Coronary Artery Risk Detection in Appalachian Communities (CARDIAC) project. Child-gender specific linear regression models showed that parent physical activity and child grade were significant predictors of parent support for physical activity in both boys and girls. Additionally in parents of girls, parent body mass index (BMI), total number of children in the home, and socioeconomic status (SES) were significant predictors of parent support for child physical activity. There was no significant difference in parental supportive behavior based on rurality; however parents of boys did report higher levels of supportive behavior than did parents of girls.

These findings suggest that parental support for girls' physical activity is more likely to vary based on other factors than is the case for boys. It is possible that physical activity in boys is seen as a higher priority in both families and in communities due to culturally prescribed stereotypes with males and sports and physical activity behavior. Thus support for physical activity may be a priority in the majority of parents of boys than it for girls across multiple circumstances. While not significant, this study also found that parents in rural areas have higher rates of support for physical activity. It could be that roots grounded in manual labor and farming in rural areas lead to greater support for physical activity. However girls in rural areas still had lower levels of support for physical activity than did boys. Future research should explore these factors further and assess interactions among multiple levels of the Social Ecological Model. Findings imply that there may be a need for targeted intervention to increase parental support in parents of girls, particularly as girls approach adolescence.
\end{abstract}




\section{DEDICATION}

I dedicate this dissertation to my husband, Jed, and my children, Jonah and Abigail. To Jed for being my biggest supporter and my best friend, to Jonah for being the very best part of everyday these past four years, and to Abigail for being my prize at the finish line. I love you all. 


\section{ACKNOWLEDGEMENTS}

I would like to give special acknowledgement to my mentor, Geri Dino. Being able to work with Dr. Dino is by far the best thing that happened to me while pursuing my PhD. Thank you Geri for your sense of humor and dedication to my education, it has been a true pleasure working with you.

Recognition is given the members of my committee: Anoop Shankar, MD, $\mathrm{PhD}$, John Giroir, Keith Zullig, PhD, and Nancy O'Hara Tompkins, PhD. I would especially like to thank Lesley Cottrell, $\mathrm{PhD}$, for going above and beyond the role of a committee member while working on this project. Your advice and guidance has been very helpful.

I would also like to thank the PhD Program Director, Keith Zullig for his hard work in setting up the program and his availability for questions and concerns. Additionally, I would like to recognize the Department of Community Medicine for housing the program.

Thanks are given to the West Virginia Prevention Research Center for being a wonderful home the past three years. I can't imagine working with a more wonderful group of people.

Additionally I would like my classmates, Janie Leary, Clifton Strange, John Blosnich, and Joe Putilla for being an incredible support system, especially in my first year.

Recognition is also given to the CARDIAC project, particularly Christa Ice and Janie Leary for use of their data and their willingness to share their time and information.

To my sisters Laura and Stacy, thank you for your support and friendship.

Finally, I would like to thank my parents, Steven and Carolyn Cox for being incredibly supportive in all areas of my life including physical activity. From sitting in freezing weather at a football game to watch a cheerleader to babysitting my children so I could finish my dissertation, I know I would not be the person I am without your love and support. 


\section{TABLE OF CONTENTS}

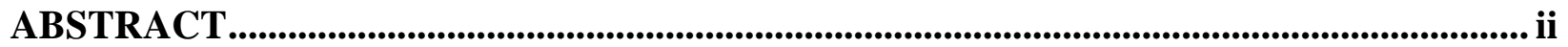

DEDICATION .......................................................................................................................ii

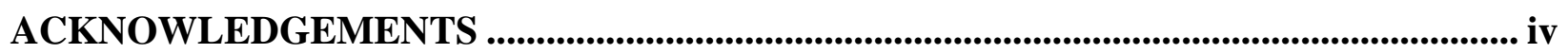

TABLE OF CONTENTS ……......................................................................................................... v

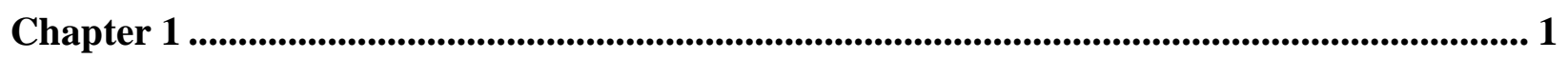

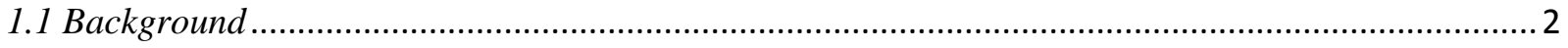

1.1.1 Benefits of Child Physical Activity ............................................................................

1.1.2 Recommendations and Rates ........................................................................................... 4

1.1.3 Child Gender and Physical Activity .................................................................................. 4

1.1.4 Physical Activity in Rural Areas ........................................................................................ 6

1.1.5 Role of Parents in Physical Activity ...............................................................................

1.2 Current Gap in the Literature …………………………………………………………... 9

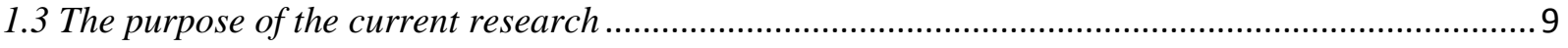

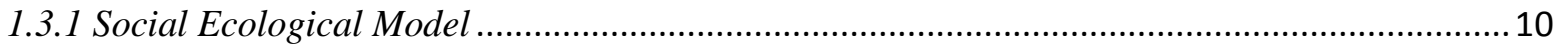

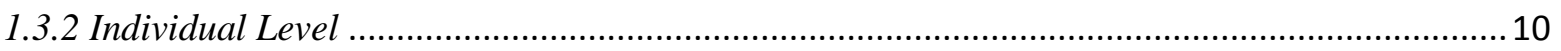

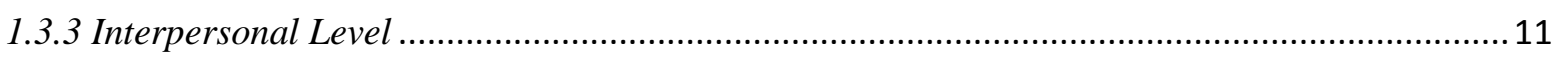

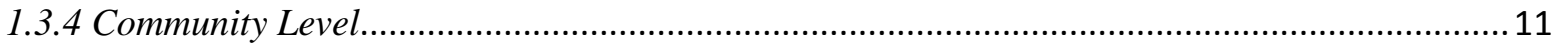

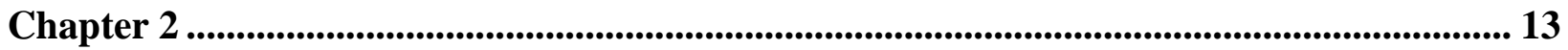

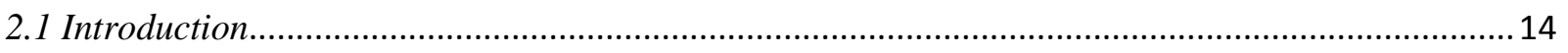

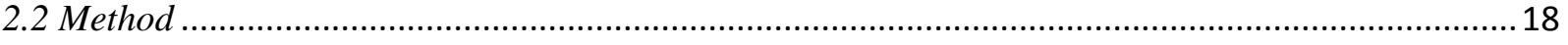

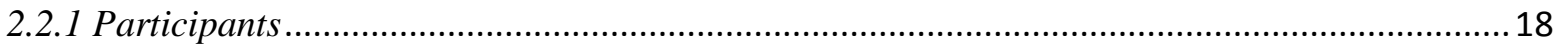

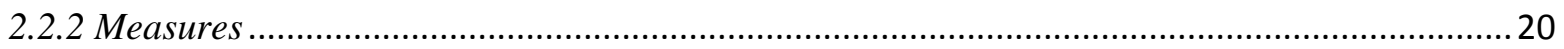

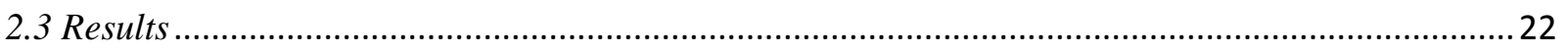

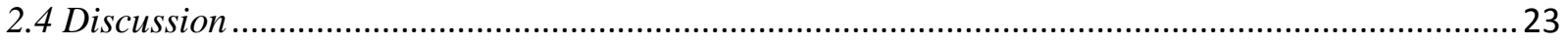

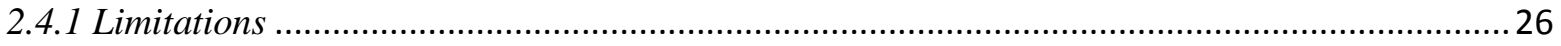

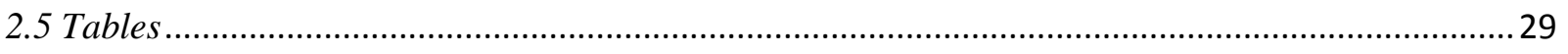

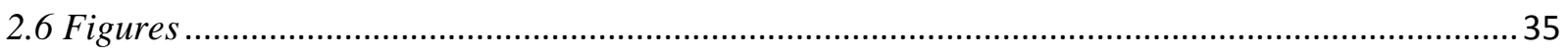

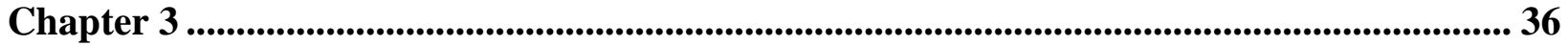

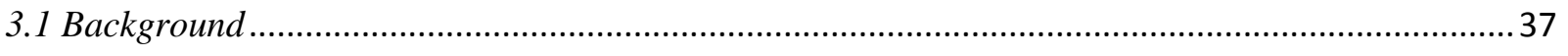

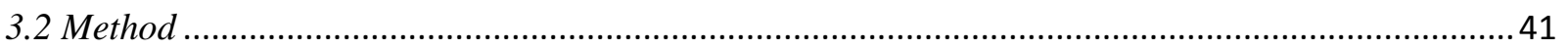




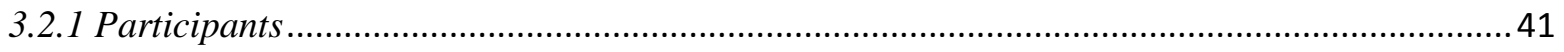

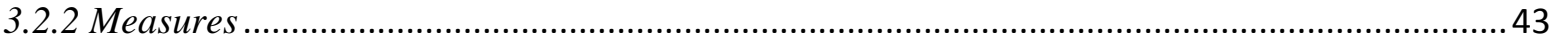

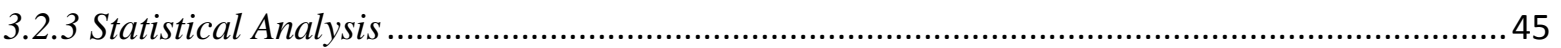

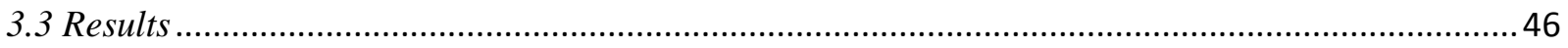

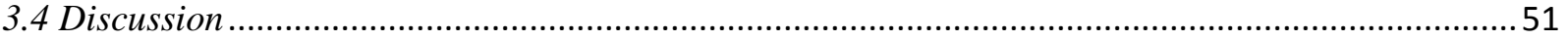

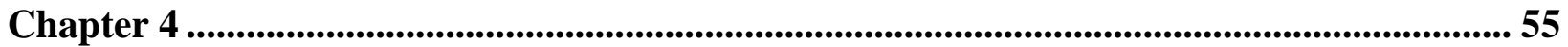

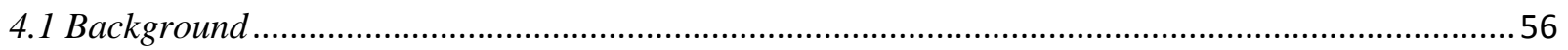

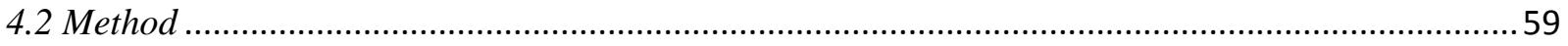

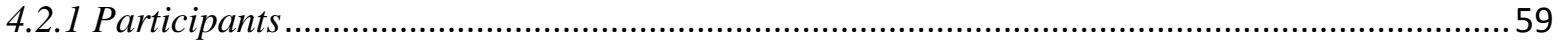

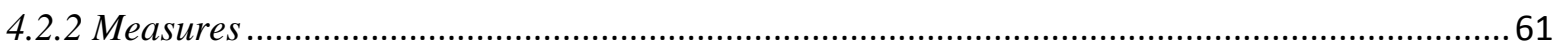

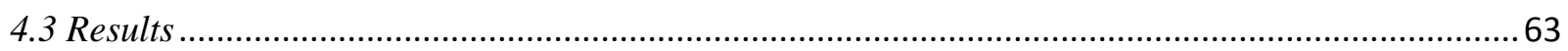

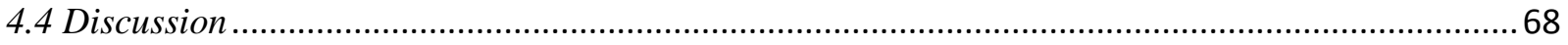

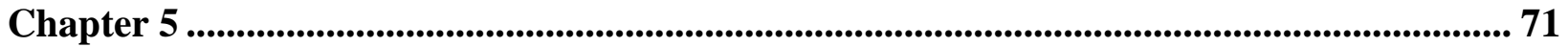

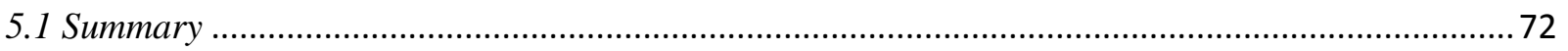

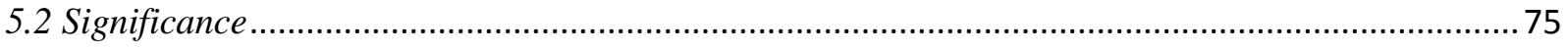

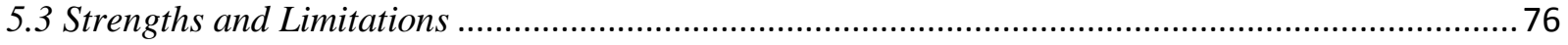

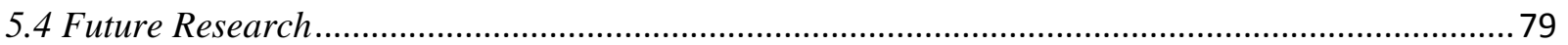

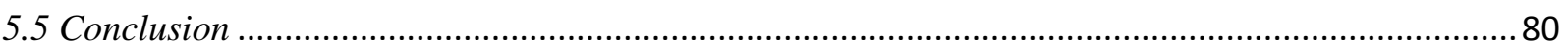

Appendix A: Rural-Urban Commuting Area Codes (RUCAs) ............................................... 82

Appendix B: Survey Questions............................................................................................................ 84

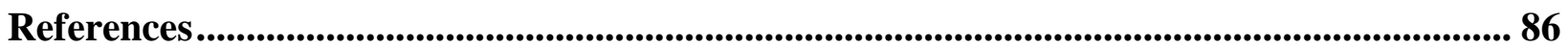


Chapter 1 


\section{Chapter 1}

\subsection{Background}

\subsubsection{Benefits of Child Physical Activity}

Childhood physical activity is a healthy lifestyle behavior with numerous benefits. With approximately one-third of children and adolescents classified as overweight or obese in the United States, [1] physical activity has been identified as instrumental in obesity prevention efforts. [2-5] Other components of obesity prevention include improving nutrition and decreasing sedentary behavior. [4] Nutrition research emphasizes increases in family meals and decreased consumption of energy-dense and low nutrient foods and sugar sweetened beverages. [6] Sedentary behavior research examines increases in behavior characterized by little movement and low energy expenditure, such as computer use, video games, and television viewing. [7, 8] The majority of studies show that screen time is inversely related to aerobic fitness in childhood. [9] Some research has found a positive correlation between screen time and childhood weight status or body mass index (BMI). [10, 11] Childhood overweight and obesity can lead to increased risk of adult obesity, [12, 13] hypertension, [14] hyperlipidemia, glucose intolerance, heart disease, cancer, and many other health conditions. [15-17] Additionally, low physical activity levels are associated with other indicators of poor health including smoking, poor nutrition, and academic performance. [18]

Positive outcomes from physical activity extend beyond obesity prevention into other physical and psychological benefits. $[19,20]$ Childhood physical activity is associated with improved metabolic health, including measures of insulin resistance, triglycerides, cholesterol/HDL ratio, and blood pressure. [21] It is effective at preventing onset of type 2 diabetes mellitus in overweight youth. [22] Adolescent physical activity has also been found to 
reduce breast cancer, decrease sedentary behaviors in adulthood and have a long-term impact on bone health. [23]

There are also mental and emotional health benefits from youth physical activity. In a large sample ( $\mathrm{N}=988)$ of adolescents (age 14-18) in Germany, physical activity was positively associated with increased physical and psychological health, and enhanced self-image. Specifically, participants with higher levels of physical activity had lower anxiety-depression levels and lower social inhibition. [24] Increased physical activity levels over a two year period coincided with improved levels of social and physical self-perception in a study of 9-14 year olds. [25] A study surveying 11, 13, and 15 year olds in North America and Europe found positive associations with physical activity and self-image, life-satisfaction, and positive parent and peer relationships. [26] In a much smaller study $(\mathrm{N}=66)$ of Hispanic fourth graders, participation in an aerobic intensity physical activity program led to lower depression scores when compared to a control group. [27] Critically, these benefits appear throughout different age groups including older childhood and into adolescence.

Of special importance to school systems and to parents, a majority of studies exploring physical activity, physical fitness, physical education, and academic performance have found a positive relationship. [28] Fifth grade children in Wood County, West Virginia, who scored in the Healthy Fitness Zone on the FITNESSGRAM test had significantly higher scores on the WESTTEST academic achievement test. [29] FITNESSGRAM is an assessment tool that is used to measure physical fitness in $4-8^{\text {th }}$ graders in West Virginia. [30] WESTTEST is the standardized testing tool that is used to measure student academic performance. [31] Authors speculate that these benefits may be due to improved endothelium-dependent vasodilation that increases oxygen to the brain. 


\subsubsection{Recommendations and Rates}

Researchers continue to try to identify appropriate levels of child physical activity, however, experts currently recommend sixty minutes of moderate to vigorous physical activity a day. [32] Unfortunately, only $34.7 \%$ of adolescents met these rates in the US in 2007. [33] Increasing the need for intervention, rates of physical activity decline throughout childhood and adolescence. [34-36] A longitudinal study following girls from ages 9-10 to 18-19, found that declines in metabolic equivalent times (METS), a common measure of physical activity, were associated with increases in BMI. [37] These findings suggest that the greater the decline of physical activity, the greater the increase in BMI. Thus, identification of ways to lessen the decline of physical activity is needed, particularly for girls.

\subsubsection{Child Gender and Physical Activity}

Gender differences and disparities in physical activity are a multifaceted and complicated area of research. Regardless of biological influences, interpersonal and environmental influences related to gender and physical activity impact boys and girls in many ways. [38, 39] To put gender differences in physical activity into context, it is important to consider gender development and current gender stereotypes and how these impact physical activity.

Gender Socialization Theories related to gender can generally be classified into three categories: biological, socialization, and cognitive.[40] Biological theories are primarily concerned with the role of genes, chromosomes and hormones and how they influence behavior. Cognitive theories focus on children's knowledge of gender and how this influences their views of gender and their actions as a result. Socialization theories examine the differential treatment of children by gender. This includes messages received from parents, grandparents, siblings, and others, along with the portrayal of males and females in media. [40-42] Adult and parent 
interactions with a child are influenced by the child's gender and parents participate in gender socialization from infancy. [42] Social Learning theory posits that learning occurs through modeling and reinforcement. [43] Thus, if children model physical activity behavior and it is seen as appropriate, they will be praised or rewarded. If it is seen as unimportant they will be reprimanded or ignored. [40] This socialization is driven by culturally-prescribed stereotypes.

Stereotypical Gender Roles Stereotypes are "fixed, oversimplified, and sometimes distorted idea[s] about a group of people." [41] While often inaccurate or incomplete, cultural stereotypes can lead to scripted positions and actions that are expected of individuals. Some common gender stereotypes are that females are warm, emotional, and weak while common male stereotypes are assertive, competitive, and strong. [41] While these stereotypical gender roles may be imposed by society, they often become integrated into one's concept of self and are part of one's identity. [44] Gender stereotypes appear to be the first stereotypes learned as children begin to differentiate between male and female in the first year of life. By the middle of the preschool years, children will identify specific objects or activities as male or female. [42] These gender roles influence development and behavior will begin to align with these stereotypes. Even language will differentiate in male or female play groups in preschool, with males having more assertive communication and females having more cooperative communication. [45]

Influence of Gender on Physical Activity Historically, physical activity and athletic behavior is classified as stereotypical masculine behavior. [46, 47] As a result, girls may not be reinforced for engaging in such behavior. Even in the womb, parents describe ultrasound pictures differently based on gender with females being described as softer, delicate, and more beautiful than are males. [48] A study examining parent expectations of infant crawling ability 
found that mothers of sons had higher expectations of their child's ability to crawl down slopes than did mothers of daughters, when in fact there was no gender difference in crawling ability. [49] This type of overestimation of boys' physical ability and underestimation of girls' physical ability illustrates how child gender can influence parent beliefs and expectations, which may, in turn, impact parenting practices.

In spite of the fact that physical activity is promoted more in boys, girls benefit greatly from physical activity and sports. In 1997, the President's Council on Physical Fitness and Sport issued a report titled Physical Activity and Sport in the Lives of Girls. This report cited the numerous benefits (physical, psychological, and academic) of physical activity and sport involvement for girls and recommended that girls be strongly supported and encouraged to participate in physical activity and sport. [50] Sport socialization fits with traditional masculine stereotypes but does not conform to traditional female stereotypes. [47] Thus, for some girls the concept of becoming a woman and becoming an athlete may be incongruent. [51] Therefore, to increase physical activity in girls, support and influence needs to be even greater and from multiple sources to overcome gender socialization. [52]

Policy and cultural efforts to decrease gender disparities in physical activity, such as the passing of Title IX in 1972, increased focus on the promotion of girls' physical activity and specific interventions have been developed to specifically target and increase physical activity. $[53,54]$ However, girls continue to have lower levels of physical activity than boys throughout childhood and adolescence. [35, 55]

\subsubsection{Physical Activity in Rural Areas}

In recent decades, opportunity for physical activity has declined for many youth due to decreases in active transportation, such as walking or riding a bike, to and from school, reduction 
in school physical education, school policy restrictions, and parental concern for safety. [56] In an effort to reverse this trend, much research has been done on ways to increase physical activity in childhood. A systematic semi-quantitative review of environmental factors influencing physical activity found correlates of physical activity include multiple aspects of the home and school environment. [57] Improved access to programs and facilities is positively associated with increased physical activity. [58] Unfortunately, availability of resources and opportunity for physical activity can be much lower in rural areas, [59] exacerbating the problem for rural children and adolescents.

Findings on childhood physical activity and obesity in rural populations are varied. A study comparing physical activity between rural and urban girls, found no difference related to residence. [60] In contrast, a comparison of rural and urban youth in Canada found differences in active transport to school and physical education opportunities. [61] A study conducted in a Midwestern state in the U.S. found increased levels of obesity in rural youth, and decreased levels of physical activity among urban youth when both were compared to a small city population. [62] Another study examining children ages 7-19 in rural Maryland found that girls with higher body fat were more likely to have higher levels of sedentary activities. This association was not present for boys. [63] These studies indicate that there may be differences in the level of physical activity and related health issues in rural environments.

\subsubsection{Role of Parents in Physical Activity}

Regardless of the terrain and rurality, parental influence on child physical activity has been researched in efforts to identify potential avenues for intervention. Many of these studies have examined the relationship of parental modeling of physical activity and exercise with childhood physical activity. There have been mixed findings in this area with some studies 
showing a positive relationship and some finding inconclusive results. [55, 64] Nonetheless, there appears to be a consistent, strong positive relationship between parental supportive behavior and child and adolescent physical activity. [58, 64, 65] This relationship is both direct and mediated through youth self-efficacy. [64]

There are multiple ways in which parents can support physical activity. Instrumental support, emotional support, and involvement appear to be the most important types of supportive behavior. [64] Instrumental support refers to acts of facilitation such as transportation, funding, and increasing access. Transportation to places for physically activity has a positive relationship with late childhood physical activity. [66-68] Emotional support includes encouragement and praise. Encouragement for physical activity has been identified as a positive correlate in several studies. [69, 70] Praise has also been found to positively influence physical activity. [67] Involvement or participation in physical activity with children is another component of parental support that influences physical activity in late childhood. [66] Mothers may provide more logistic support, such as transportation, paying fees, etc., whereas fathers are involved in more modeling and active play with their children. [71] All of these types of support have a positive relationship with youth physical activity.

Studies examining parental supportive behavior generally find that boys receive greater levels of support than do girls. [64, 67, 72] While boys might receive higher levels of parental support, greater parental support is also associated with increased physical activity in girls. [71, 73]

The impact of parental support for physical activity appears to diminish as children enter and progress through adolescence. $[64,74]$ This coincides with typical developmental social progression in adolescence where peers take on a more influential role. [75] This increases the 
importance of identifying factors that influence parental support in childhood, when parents have the greatest influence. A longitudinal assessment of girls in grades eight, nine, and twelve showed that lower levels of family support in the eighth grade resulted in a more rapid decline in physical activity by the twelfth grade. [76] If parental support can be increased when parents have the greatest impact, we could stem the decline of physical activity throughout adolescence.

\subsection{Current Gap in the Literature}

Several existing physical activity interventions encourage parent support in an effort to increase physical activity. [39,77] To effectively improve parental supportive behavior, more information is needed about factors that influence parental support. Very little is known about how personal health risk, family composition and rurality influence parental support. Since health behavior is impacted by multiple levels, [78] the Social Ecological Model was used to guide this project. Additionally, the impact of the physical environment on factors related to obesity and physical activity is an area of study where more research is needed. Rural areas present unique benefits and challenges for the individuals who reside in them. Rural adults have been found to have higher rates of obesity and lower levels of physical activity when compared to urban adults. $[79,80]$ A study examining disparities in childhood obesity based on geographic region and state found that children in West Virginia have twice the odds of being obese than children in Utah, the state with the lowest rates. [81] Ultimately, there are many unanswered questions on the impact of the unique mountainous environment in Appalachia on child physical activity and related behavior.

\subsection{The purpose of the current research}

The aim of this project was to identify factors that may influence parental supportive behavior at three levels of the Social Ecological Model. The Social Ecological Model (see 
Figure 1) recognizes that behavior is a result of a complex interaction of internal and external factors. [78] Specifically, the levels identified were the individual, interpersonal, organizational, community, and policy levels. The Social Ecological Model has been used to explore multiple influences on physical activity. [39, 82] Numerous studies have identified the importance of parental supportive behavior, $[58,83,84]$ yet, very little is known about what influences parental support. To maximize intervention efforts in childhood physical activity and obesity, factors that influence parental support must be identified.

\subsubsection{Social Ecological Model}

Figure 1.1: Levels of the Social Ecological Model

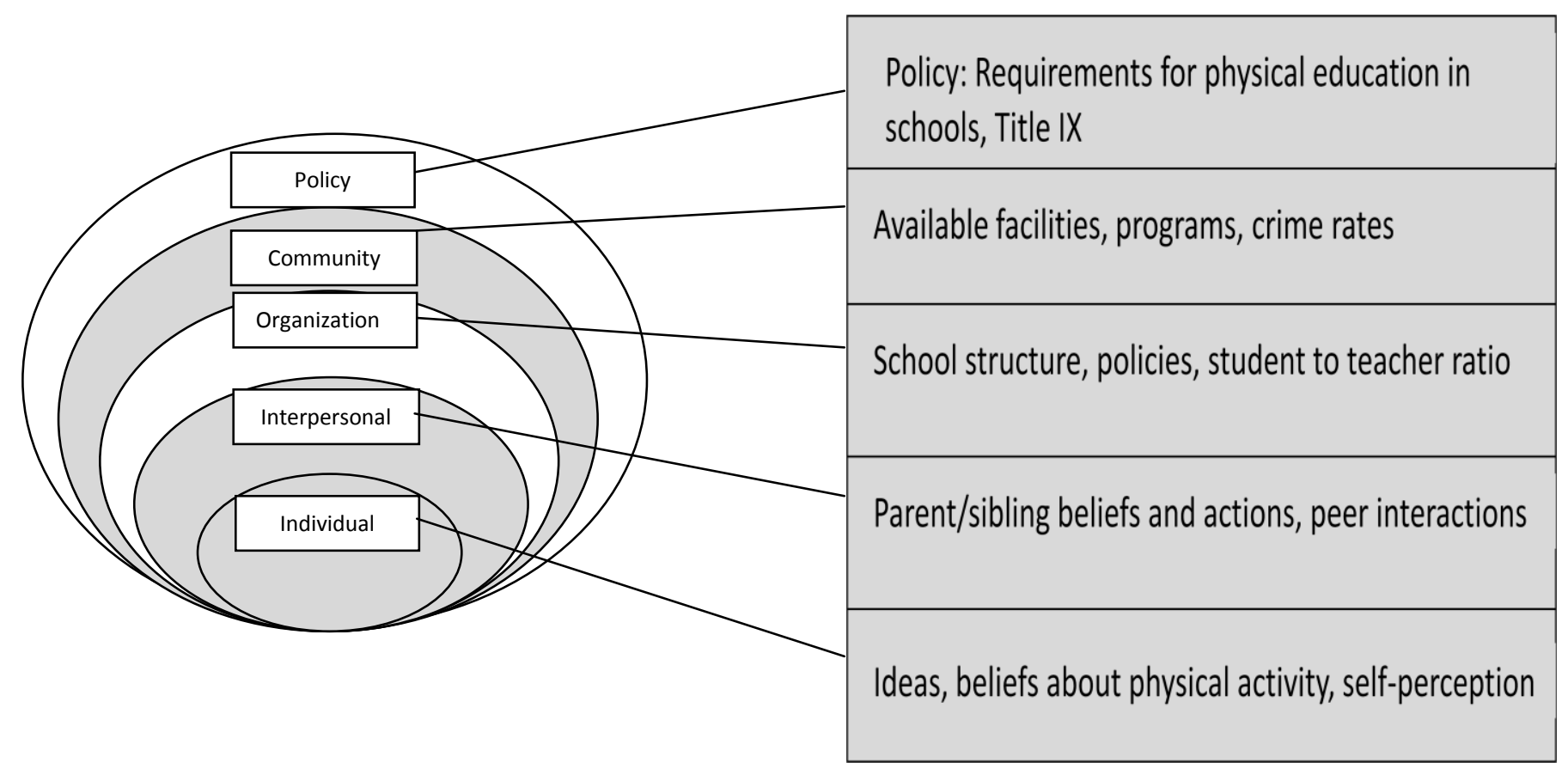

\subsubsection{Individual Level}

Parents influence health behavior in children through modeling physical activity and nutrition behavior, facilitating opportunities for physical activity and healthy eating, and through their influence in family meals and eating habits. [5] Richards and colleagues found that poor parent health, as reported by the mother, increased the likelihood of persistent inactivity in 
adolescents. [85] The authors theorized that parental health could impact parental supportive behavior. Trost and colleagues found that parental supportive behavior mediated the relationship between parental physical activity and child physical activity. [83] The study detailed in Chapter 2 describes how individual parent health risk behavior, specifically BMI, physical activity, nutrition, and smoking, influences parent support for child physical activity.

\subsubsection{Interpersonal Level}

Family composition, i.e. number of children, child gender, and number of parents, has been found to have an impact on minutes per day in youth physical activity. One study found that girls with a sibling had higher levels of moderate to vigorous physical activity [86] while a study of adolescents in England found that having a sister was negatively related to weekend physical activity in boys. [87] This suggests that the presence and gender of siblings could impact child physical activity. Since there is an established relationship between childhood physical activity and parental supportive behavior, the study detailed in Chapter 3 explored the influence of multiple children and child gender on parental supportive behavior in parents of boys and girls.

\subsubsection{Community Level}

Rural communities, in general, present unique challenges concerning the availability and opportunity for physical activity. [59] Lack of sidewalks, walking and biking trails, and decreased access due to remote location are examples of such challenges. Youth living in rural areas are more likely to be overweight than those living in suburban areas. [88] The effect of the rural environment on parental supportive behavior has not been researched. Previous studies have recommended interventions to increase levels of parental supportive behavior both at the individual and community level. [83] The study detailed in Chapter 4 compared rates of parental 
supportive behavior for child physical activity in boys and girls in rural and non-rural communities.

In summary, while we know that parental supportive behavior is a positive influence on child physical activity, very little is known about what influences parental support. [83, 84] This project explored specific influences on parental supportive behavior at the individual (health behavior), interpersonal (family composition), and community (rurality) levels of the Social Ecological Model. Findings increase the current knowledge about parental supportive behavior for physical activity in boys and girls. 
Chapter 2 


\section{Chapter 2}

Influence of parent health risk behavior on support for child physical activity

\subsection{Introduction}

Childhood physical activity is a healthy lifestyle behavior with numerous benefits. Along with nutrition, physical activity has been identified as instrumental in obesity prevention. [2-5] Childhood physical activity can also lead to physiological benefits, [19, 20] including improved metabolic health, specifically measures of insulin resistance, triglycerides, cholesterol/HDL ratio, and blood pressure. [21] It is also effective at preventing onset of type 2 diabetes mellitus in overweight youth. [22] Psychological benefits of childhood physical activity include enhanced self-image, improved self-perception, lower anxiety-depression levels, and lower social inhibition. [24, 25] There also appear to be academic benefits associated with physical activity, physical fitness, and physical education [28] specifically, children who are more physically active perform better in the classroom. This finding was also present in a study conducted in Wood County, WV where children who scored higher on the FITNESSGRAM physical fitness test, were more likely to score high on the WESTTEST, standardized academic testing. [29-31] While the cause behind this relationship is unknown, the authors cite similar benefits in older adult populations and speculate that it may be due to improved endotheliumdependent vasodilation that increases oxygen to the brain.

Unfortunately, rates of physical activity decline throughout childhood and adolescence. [34-36] Some findings suggest this decline is greater among girls than it is among boys. [89] This could be related to emerging gender identity in adolescence and incongruent beliefs about physical activity and identifying oneself as a woman. [51] A longitudinal study following girls from ages 9-10 to 18-19, found that declines in metabolic equivalent times (METS), a common measure of physical activity, were associated with increases in body mass index (BMI). [37] 
These findings suggest that the greater the decline in physical activity, the greater the increase in BMI. Thus, identification of interventions to address disparities in physical activity is needed.

Parents can have a crucial role in promoting childhood physical activity. Multiple studies have found a consistent and strong positive relationship between parental supportive behavior and child and adolescent physical activity. [58,64,65] There are several ways in which parents can support physical activity. To develop a composite measure of parental support, Prochaska et al. included instrumental, emotional, and modeling forms of supportive behavior. [90] Instrumental support refers to acts of facilitation such as transportation, funding, and increasing access. Transportation to places for physically activity has a positive relationship with childhood physical activity. [66-68] Emotional support includes encouragement and praise; encouragement for physical activity has been identified as a positive correlate with child physical activity in several studies. [69, 70] Praise has also been found to positively influence child physical activity. [67] Parental involvement or participation in physical activity with children is another component of parental support that influences physical activity in late childhood. [66] Previous research shows that mothers, more than fathers, provide logistic support such as transportation and paying fees, whereas fathers are more involved in modeling and active play with their children. [71] All of these types of support have a positive relationship with youth physical activity.

Studies examining parental supportive behavior generally find that boys receive greater levels of support for physical activity than do girls. [64, 67, 72] While boys might receive higher levels of parental support on average, greater parental support for physical activity is associated with increased physical activity in girls. $[71,73]$ Since physical activity is viewed as a more masculine activity, boys could receive greater levels of support and receive greater reinforcement 
for being physically active. According to social learning theory, children learn through modeling and reinforcement. [43] Parent messages to children could be driven by gender-related stereotypes regarding physical activity. [40-42] Due to numerous physical, psychological, and academic benefits of physical activity for girls, [50] this gender-based socialization regarding parental encouragement for physical activity could lead to other health disparities for girls and women that are related to physical activity and sedentary lifestyle, such as heart disease and depression. [91]

A longitudinal assessment of girls in grades 8,9 , and 12 showed that lower levels of family support in the 8th grade resulted in a more rapid decline in physical activity by the 12th grade. [76] Research has also found that the impact of parental support for physical activity appears to diminish as children enter and progress through adolescence. [64, 74] This finding increases the importance of identifying factors that influence parental support in childhood, when parents have the greatest influence. [64, 74, 76] If parental support can be increased when parents have the greatest impact, then we could stem the decline of physical activity throughout adolescence.

Although numerous studies have identified the importance of parental supportive behavior, $[58,83,84]$ we know very little about what influences parental support. One potential influence is parental health. Richards and colleagues found that poor parent health, as reported by mothers, increased the likelihood of persistent inactivity in adolescents. [85] The authors theorized that parental health could impact parental supportive behavior for physical activity. Physical inactivity, obesity, and smoking can be major contributors to adult/parent health. [92, 93] Therefore, research examining the association among these health risks and support for physical activity in parents seems warranted. 
The present study explored the influence of individual parent health risk factors on parental supportive behavior for child physical activity. Previous findings identified a relationship between parent physical activity and support for child physical activity. [83] It is also known that parental obesity is positively related to childhood obesity. [94-96] Fruit and vegetable consumption was examined due to the impact of diet on personal health and obesity. [97] We included parent smoking for several reasons. First, it is the most preventable cause of disease and death in the US. [92] Second, there is emerging evidence that parental smoking may increase the likelihood of childhood obesity. [96, 98] Third, parent smoking negatively impacts children through exposure to second hand smoke and by modeling unhealthy behavior. [99]

Socioeconomic status (SES) appears to have a positive relationship with physical activity $[64,100]$ : families with greater resources tend to have children with higher levels of physical activity. Additionally, the availability of financial resources would likely have an impact on components of parental support for child physical activity such as transportation. Transportation can be a problem for poorer families due to fewer vehicles per family and the rising cost of gasoline. Particularly in rural areas, transportation can be a problem due to the lack of public transportation. [59] While it is not the primary variable of interest of this paper, it was important to include SES as a covariate in order to control for any effects it might have on parental support for child physical activity. Grade is also an important covariate to include due to decreases in the influence of parental support as children age. [64, 74]

If specific characteristics of parents with low levels of supportive behavior for physical activity can be identified, these parents can then be targeted for prevention interventions or reached through more specific means. Emphasis on parental supportive behavior for child physical activity could be built into existing interventions working to decrease poor parental 
health. Parents with poor health behavior could also be targeted in recruitment for child physical activity interventions. Further, this information could be helpful to parents who have unhealthy behaviors but want to improve their children's health.

The purpose of this study was to identify the influence of parent health behaviors on parent support for physical activity in parents of boys and parents of girls. This study examined this influence through secondary analysis of cross-sectional data collected through the Coronary Artery Risk Detection in Appalachian Communities (CARDIAC) project. The CARDIAC project is a screening initiative that works to identify and combat chronic disease risk in West Virginia. CARDIAC screens several age groups in West Virginia including kindergarten, $2^{\text {nd }}$, and $5^{\text {th }}$ graders.

Based on previous literature regarding poor parent health and lower levels of adolescent physical activity, [85] we predicted that higher levels of parent physical activity and fruit and vegetable consumption would positively predict parental supportive behavior, and smoking and BMI would negatively predict parental supportive behavior. Due to the finding that the influence of parental supportive behavior decreases with age, $[64,74]$ we predicted that grade (age) would be a negative predictor of parental supportive behavior. Finally, due to findings that SES is positively correlated with child physical activity, $[64,100]$ we expected that socioeconomic status would be a positive predictor of parental supportive behavior.

\subsection{Method}

\subsubsection{Participants}

The study sample consisted of 773 parents of kindergarten, $2^{\text {nd }}$, and $5^{\text {th }}$ grade participants who completed CARDIAC screening surveys for the 2008/2009 and 2009/2010 school years in eight West Virginia counties (Braxton, Clay, Marshall, Mason, Monongalia, Pendleton, Taylor, 
and Lincoln). These eight counties were selected for having geographical dispersion and logistically strong site coordinators rather than for state-wide representativeness. West Virginia is a largely rural state entirely encompassed in Appalachia. West Virginia has elevated rates of chronic disease and chronic disease risk behaviors. [101] All students in select grades in West Virginia are eligible for CARDIAC screening. To identify participating children for the 2008/2009 and 2009/2010 school years, parents were sent a consent form and a screening form through their child's school. Participating parents/guardians signed the consent form, completed the parent sections of the screening instrument and returned them to their child's school through their child. Parents provided information about their child's and their family's health history on the screening form. The remainder of the form was completed by a member of the CARDIAC team on the day of the screening, including detailed information about the child's weight, height, and presence of acanthosis nigricans (AN). AN is a hyper-pigmented skin in the base of the neck, axillae or groin typically associated with hyper insulinemia. In $5^{\text {th }}$ graders, blood pressure and blood samples were drawn to further measure physiological health markers such as cholesterol and triglycerides. Data from the screening was analyzed and a summary of the child's health findings was generated by the CARDIAC team and returned to parents along with a survey assessing parental attitudes, beliefs, and behaviors related to physical activity, nutrition, and obesity. In the 2008/2009 school year parents were sent surveys through the United States Postal Service to the child's place of residence along with screening results. In the 2009/2010 school year, parents were sent these items through their child's school. No significant differences in levels of parental supportive behavior were found between screening years. For the 2008/2009 and 2009/2010 school years, 4,695 kindergarten, $2^{\text {nd }}$, and $5^{\text {th }}$ graders completed the screening and were sent a packet with surveys. A total of 776 parent surveys were completed for a response 
rate of $16.5 \%$ (see Figure I). CARDIAC research protocol has been approved by the West Virginia University Internal Review Board (IRB). Additional information on the CARDIAC project has been previously published. [102-105]

\subsubsection{Measures}

Parental Supportive Behavior The outcome variable, parental supportive behavior, was measured with a composite scale initially developed for the Amherst Health and Activity Study [90] was adapted to measure parental supportive behavior based on five factors: transportation, encouragement, praise, watching, and participation (see Table 2.1). Response options range from never/almost never (1) to daily (5) on a five-point Likert-type scale. Cronbach's alpha for the composite scale was calculated to be .71 in this sample. Scores on the five questions were averaged to obtain a composite score ranging from 1-5. Participants had to complete at least three of the five questions to be given a composite score. An average was taken rather than a sum to include more participants in the final sample. While this measure was used previously, we were unfortunately unable to compare to other studies that have used this measure due to the fact that previous studies used a sum of each individual question and we used an average.

Parent Health Measures Parent BMI was calculated based on self-reported height and weight data from the parent survey. Parental smoking was assessed with the following question from the Behavioral Risk Factor Surveillance Survey (BRFSS) [106]: During the past 30 days, on how many days did you smoke cigarettes? Responses ranged from 0 (0 days) to 6 (every day) and were then dichotomized into smoker and non-smoker based on if they had smoked on any day in the previous month. [107, 108] Physical activity was assessed with the following two questions from the Youth Risk Behavior Surveillance Survey (YRBS) [109]: “On how many of the past 7 days did YOU exercise or participate in physical activities for at least 20 minutes that 
made you sweat and breathe hard, such as basketball, soccer, running, swimming laps, fast bicycling, fast dancing, or similar aerobic activities?" And "On how many of the past 7 days did you participate in physical activity for at least 30 minutes that did NOT make you sweat or breathe hard, such as fast walking, slow bicycling, skating, pushing a lawn mower, or mopping floors?" Response options ranged from 0 days to 7 days. The questions were then combined via the following formula to obtain a proxy measure for minutes per week spent in physical activity: $((($ vigorous PA days/week * 20) *2)+(moderate PA days/week* 30)). [110] The BRFSS and YRBS are surveys developed by the Center for Disease Control and are used for nationwide surveillance. These measures are commonly used in health behavior research. [111, 112] Parent nutrition was measured by the reported number of fruit and vegetables consumed daily measured with the following question: How many servings of fruits and/or vegetables do YOU eat every day? Self-reported fruit and vegetable consumption has been found to be an effective measure of nutrition in a clinical sample [113]; estimation of fruit and vegetable consumption were combined into one question in this survey. Two participants were excluded from analysis after reporting consuming 34 and 16 servings of fruits and vegetables a day.

Demographic Measures Socio-economic status was measured by child participation in the free and reduced lunch program. [114] Initially $7 \%$ of parent data was missing for this specific question. The missing scores were calculated based on household size and annual income to determine if they would qualify for free and reduced lunch based on West Virginia Department of Education guidelines for 2009/2010. [115] This reduced missingness to $1 \%$. Annual income was measured with the following question: What is your approximate yearly household income? Participants had eight response options ranging from $<10,000$ to $100,000 \mathrm{or}$ more. Household size was calculated based on two questions: What are the ages of your 
children (18 and under) in your household (each response was converted to a one and then all responses were summed to obtain the total number of children in the household). This was then added to the following question: How many adults 19 and older live in your household?

Statistical Analysis Descriptive statistics were used to summarize demographic information. Child gender-specific correlation matrices and linear regression models were conducted to assess the relationships between variables and impact of parent health behavior, free or reduced lunch eligibility, and grade on parental supportive behavior. All analyses were conducted in PASW 18 (formerly SPSS). All variables had missing data $<5 \%$; as a result methods of replacement such as mean substitution or imputation were unnecessary. [116] Listwise deletion was used in analysis.

\subsection{Results}

A total of 773 parents were included in analysis; 387 were parents of girls and 386 were parents of boys. The majority of parents were mothers (90.7\%), parents of kindergarteners (60.2\%), high SES (57.4\%), and non-smokers (72.2\%). Mean parent BMI was 27.7 and mean parent age was 35.9. The sample was primarily white (90\%). Mean parental supportive behavior was 3.7 (See table 2.2). When compared to WV BRFSS [106] data from 2009, the study sample appears to be different with a higher percentage meeting physical activity and nutrition recommendations and lower percentages of obesity and overweight. A much higher percentage (64.3\%) of the study sample reported meeting physical activity recommendations (30+ minutes of moderate physical activity five or more days per week, or vigorous physical activity for $20+$ minutes three or more days per week) compared to $35.2 \%$ on the WV BRFSS. There were also lower percentages of overweight and obesity in the study sample. Additionally, a greater percent of the study sample (22.8\%) reported consuming 5 or more fruits and 
vegetables per day compared to that reported in the WV BRFSS (16.2\%). There was a slightly higher percentage of current smokers in the study sample $27.8 \%$ compared to $25.6 \%$ in the WV BRFSS. (See table 2.3)

In parents of girls, bivariate correlations using a Bonferonni correction showed a positive relationship between parental supportive behavior and parental physical activity $(\mathrm{r}=.331 ; \mathrm{p} \leq$ $.01)$. For parents of boys, there was a positive relationship between parental supportive behavior and parent physical activity $(\mathrm{r}=.294 ; \mathrm{p} \leq .01)($ see table 2.4$)$.

Child-gender specific linear regression models were evaluated with parental supportive behavior as the criterion variable and SES, grade, parent physical activity, parent BMI, parent fruit and vegetable consumption, and parent smoking status as predictor variables. All variables were entered into the model at the same time due to the exploratory nature of the research question. [116] Assumptions such as normality, outliers, linearity, multicolinearity, and homoscedasticity were evaluated. All were in range and no transformations were performed.

The first model (parents of female children) was significant $(\mathrm{F}(6,342)=10.12, p<.001)$ with an adjusted $\mathrm{R}^{2}$ of .138 . (See table 2.5 ). Child grade $t(342)=-2.273, p<.05$, parent physical activity $t(342)=5.714, p<.01$, and parent BMI $t(342)=2.958, p<.01$, were significant predictors. (See table 2.5)

The second model (parents of male children) was also significant $(\mathrm{F}(6,349)=7.014, p<$ .001) with an adjusted $\mathrm{R}^{2}$ of .09 (See table 2.6). Parent physical activity was the only significant predictor in the model $t(349)=5.319, p<.01 .($ See table 2.6$)$

\subsection{Discussion}

We hypothesized that parent health behavior would influence parental supportive behavior. Our findings indicate that parent smoking appears to be unrelated to parental 
supportive behavior. This might be due to the low number of smokers in the study $(27.8 \%)$ restricting the range and resulting in a loss of power or that a dichotomous measure was used instead of a continuous one also resulting in a loss of power. Future research should study a larger sample of smokers to examine if there is a dose-response effect. In contrast, fruit and vegetable consumption was positively correlated with parental supportive behavior in our bivariate correlations. However, it did not significantly predict parental support for physical activity in either parents of boys or parents of girls in the regression model that included physical activity, BMI, SES, and child grade. Thus, it is likely that one of the other factors, potentially BMI, is controlling for the effect of fruit and vegetable consumption. As expected, parent physical activity was positively associated with parental supportive behavior for child physical activity in parents of boys and girls. This is consistent with previous findings. [83] Contrary to expectations, we found that parental BMI was positively associated with support for girls' physical activity in the regression model. This influence was not present for parents of boys. As the sample is mostly mothers, those who are more overweight might have heightened awareness and concern for their daughters in an effort to prevent them from being overweight. In support of this, previous research has found that in mothers who are overweight, concern for their daughters' weight can predict restrictive eating parenting practices, while controlling for the daughters' actual weight status. [117] Perhaps this concern can also influence parental supportive behavior for girls' physical activity.

We also hypothesized that grade would be a negative predictor of parental support due to previous findings that the influence of parental support decreases with age. $[64,67]$ Our findings indicate that there is a negative correlation between these two factors for both parents of boys and parents of girls. This is consistent with other findings that parental influence declines as 
children age. Additionally, in parents of girls, grade negatively predicted parental supportive behavior; as girls age, levels of support significantly decline. This suggests a need to emphasize parental support for girls in late childhood and early adolescence. Due to previously mentioned gender differences in child physical activity, increasing and maintaining parental support as girls age could help to eliminate this disparity. Other factors that also decrease physical activity such as early physical maturation $[118,119]$ could coincide with natural decreases in physical activity as girls age and cause some subgroups to be at even greater risk for physical activity decline. Perhaps the mental and emotional pressure that accompanies the physical changes associated with maturation in girls leads to increases in self-consciousness which contributes to declines in physical activity. A finding that parent support for physical activity is less in parents of older girls is even more troubling in light of this research. Targeted intervention may be needed to increase parental support among girls who mature early.

Our final hypothesis that socioeconomic status would positively predict parental supportive behavior was not supported. There was actually a negative correlation in parents of girls between SES and parental support of physical activity; lower SES was related to higher levels of parental support in girls. However, SES was not a significant predictor in either parents of girls or parents of boys when controlling for other factors. A study done by Epstein and colleagues found that SES was positively correlated with child physical activity, however their sample consisted of overweight children in a different region of the United State, [100] thus the sample used in this study could be different.

Future studies should examine the interaction of parental supportive behavior and BMI among parents of girls. Potential factors such as increased awareness of health issues associated with overweight and obesity and desire to provide a better life for their child might be mediating 
the relationship between parental BMI and parental supportive behavior for child physical activity. Another possibility is that there is increased pressure on girls concerning weight status. Also, parents, especially mothers, which were the majority of respondents, who are overweight may have heightened concern that their daughter may also become overweight. Future studies should also examine the impact of poor parental health outcomes on parental supportive behavior. This study examined parental health behavior exclusively, but was unable to examine actual health disorders. Perhaps parents experiencing chronic disease find it more difficult to provide supportive behavior for physical activity, such as transportation, because they have greater time and financial constraints due to medical treatment or they possess less energy to provide support due to combating illness. Additionally, future studies should examine the role of SES and utilize additional measures of socioeconomic status such as parent education. In WV there can be low employment rates and decreased job availability. [120] Thus it is possible that some parents who are more educated are unemployed or employed below their education level.

\subsubsection{Limitations}

All information is based on self-report including parent height and weight. The sample consisted primarily of mothers, whose responses may differ from those of fathers, including variation based on child gender. Mothers of daughters may be more concerned about child weight status than mothers of sons due to experiencing the body image pressure associated with being a woman. Women in American culture are more likely to perceive themselves as overweight. [121] The physical activity questions used to measure parent physical activity were initially developed for the YRBS, an adolescent survey. However, they are similar to the BRFSS questions on vigorous and moderate physical activity; but utilize response options of 20 or 30 minute increments as opposed to 10 minute increments on the BRFSS. As the YRBS is a written 
survey, the format of the questions lends itself better to the current study methodology. The study had a low response rate and therefore may not be generalizable to other populations. It is likely that parents who completed the survey are different from those who did not. The former may be more health conscious or attentive to their child's health than are those who did not complete the survey. Criqui and colleagues found that non-respondents on a mail survey had higher rates of cardiovascular disease risk such as smoking. [122] Our survey assessed similar behaviors, thus non-respondents in our study might also have elevated chronic disease risk. Further, when compared to the WV BRFSS, the study sample appeared to be very different, particularly concerning physical activity behavior. Roughly two thirds of the study sample met physical activity recommendations compared to only one third of the WV BRFSS sample. There was also a higher percentage of individuals consuming the recommended amount of fruits and vegetables per day and lower percentages of individuals who were overweight or obese. Another problem associated with the low response rate is that some of the findings may be conservative and the influence could be stronger than what was found in this sample. Additionally, with selfreport questions there is often a problem with social desirability, i.e. respondents answering questions to portray themselves in a more positive light [123] or in a way that is more in line with societal norms. [124] Thus parents might report that they have higher levels of support because they believe this is what they should do or what society expects of them. This could be a particular problem in our study as women tend to have Previous studies that utilized this parental supportive behavior measure used a sum of responses to the five parental supportive behavior questions, out study however used an average of the five questions to be able to include more parents in the analysis. Thus we are unable to compare our responses to previous studies on parental supportive behavior. 
It should be noted that this sample consists entirely of parents living in West Virginia. West Virginia is a largely rural state entirely encompassed in Appalachia. While rich in culture, West Virginia has elevated rates of chronic disease and chronic disease risk [101] and has a higher percentage than the national average of individuals and families living in poverty. [120] It is possible that regional influences and characteristics would make this population different from others.

The positive association between parental BMI and support for child physical activity leads to several interesting questions for this field of research. Findings suggest that parent support for girls' physical activity may be more influenced by parental health than it is for parents of boys. Previous literature shows that girls have lower rates of physical activity than do boys [35, 55] and girls also received lower levels of parental support for physical activity. [64, 67, 72] In light of this research, our finding that supportive behavior in parents of girls has more significant influences is not surprising. It could be that there is greater support in the community for boys' physical activity and the overall social structure is designed to enable physical activity in boys because of gender stereotypes around physical activity. Conversely physical activity in girls' may be seen as less of a priority and support from parents is therefore more difficult to maintain. 


\begin{tabular}{|l|l|}
\hline \multicolumn{2}{|l|}{ Table 2.1: Parental Supportive Behavior Scale } \\
\hline Construct & Question: Please indicate how often you: \\
\hline Transportation & Transport your child to a place to be physically active \\
\hline Encouragement & Encourage your child to be physically active \\
\hline Praise & Praise your child for being physically active \\
\hline Watching & Watch your child play sports or be physically active \\
\hline Participation & Take part in physical activity with your child \\
\hline Response Options: Never/Almost never (1); Monthly (2), Weekly (3), Almost Daily (4), Daily \\
(5)
\end{tabular}


Table 2.2 Participant Demographics

\begin{tabular}{|c|c|c|c|}
\hline & $\begin{array}{l}\text { Combined } \\
\mathrm{N}(\%)\end{array}$ & $\begin{array}{l}\text { Girls } \\
\mathrm{N}(\%)\end{array}$ & $\begin{array}{l}\text { Boys } \\
\mathrm{N}(\%)\end{array}$ \\
\hline $\mathrm{N}$ & 773 & 387 & 386 \\
\hline Mean Parent Age & 35.9 & 35.6 & 36.2 \\
\hline \multicolumn{4}{|l|}{ Who completed form } \\
\hline Mothers & $701(90.7 \%)$ & $353(91.2 \%)$ & $348(90.2 \%)$ \\
\hline Fathers & $40(5.2 \%)$ & $17(4.4 \%)$ & $23(6.0 \%)$ \\
\hline Other & $24(3.1 \%)$ & $14(3.6 \%)$ & $10(2.6 \%)$ \\
\hline \multicolumn{4}{|l|}{ Grade } \\
\hline Kindergarten & $465(60.2 \%)$ & $217(56.1 \%)$ & $248(64.2 \%)$ \\
\hline Second & $180(23.3 \%)$ & $98(25.3 \%)$ & $82(21.2 \%)$ \\
\hline Fifth & $128(16.6 \%)$ & $72(18.6 \%)$ & $56(14.5 \%)$ \\
\hline \multicolumn{4}{|l|}{ Free or reduced lunch } \\
\hline Eligible (Low SES) & $320(41.4 \%)$ & $161(41.6 \%)$ & $159(41.2 \%)$ \\
\hline Not Eligible (High SES) & $444(57.4 \%)$ & $220(56.8 \%)$ & $224(58.0 \%)$ \\
\hline Mean Parent BMI & 27.7 & 27.7 & 27.7 \\
\hline \multicolumn{4}{|l|}{ Current Smoker } \\
\hline Yes & $215(27.8 \%)$ & $101(26.1 \%)$ & $114(29.5 \%)$ \\
\hline No & $558(72.2 \%)$ & $286(73.9 \%)$ & $272(70.5 \%)$ \\
\hline $\begin{array}{l}\text { Mean Parental Supportive } \\
\text { Behavior (Range: } 1-5 \text { ) }\end{array}$ & 3.70 & 3.64 & 3.77 \\
\hline
\end{tabular}

$\mathrm{N}=$ Number 
Table 2.3: Summary of health behaviors among the study sample and the WV BRFSS representative sample

\begin{tabular}{l|cc}
\hline & Study Sample & WV(BRFSS 2009) \\
\hline Physical activity (percent meeting recommendations) & $64.3 \%$ & $35.2 \%$ \\
Obese (BMI $\geq 30)$ & $27.0 \%$ & $31.7 \%$ \\
Overweight (BMI 25-29.99) & $27.9 \%$ & $35.8 \%$ \\
Current smokers & $27.8 \%$ & $25.6 \%$ \\
5 or more Fruits and Vegetables a day & $22.8 \%$ & $16.2 \%$ \\
\hline
\end{tabular}


Table 2.4: Child gender-specific bivariate correlations with Bonferroni correction

\begin{tabular}{|c|c|c|c|c|c|c|c|c|c|c|c|c|c|}
\hline \multirow[b]{2}{*}{ Factors } & \multicolumn{6}{|c|}{ Parents of Girls } & \multicolumn{7}{|c|}{ Parents of Boys } \\
\hline & 12 & 3 & 4 & 5 & 6 & 7 & 1 & 2 & 3 & 4 & 5 & 6 & 7 \\
\hline 1. Grade & $1 \quad .051$ & -.035 & -.017 & .000 & -.056 & -.107 & 1 & .061 & -.078 & .029 & .013 & .080 & -.125 \\
\hline $\begin{array}{l}\text { 2. Free and reduced lunch eligible } \\
\text { (SES) }\end{array}$ & 1 & .024 & $-.183 *$ & .108 & $-.403 *$ & -.101 & & 1 & -.006 & $-.234^{*}$ & .126 & $-.314 *$ & -.014 \\
\hline 3. Parent Physical Activity & & 1 & -.166 & $.263^{*}$ & .071 & $.331 *$ & & & 1 & -.157 & $.258 *$ & .100 & $.294 *$ \\
\hline 4. Parent Body Mass Index & & & 1 & -.021 & .007 & .074 & & & & 1 & -.006 & .038 & -.057 \\
\hline 5. Parent Fruit/Vegetable servings & & & & 1 & -.173 & .134 & & & & & 1 & -.114 & .148 \\
\hline 6. Smoking & & & & & 1 & .081 & & & & & & 1 & -.035 \\
\hline 7. Parental Supportive Behavior & & & & & & 1 & & & & & & & 1 \\
\hline
\end{tabular}

$* \mathrm{p} \leq .002$ 
Table 2.5: Predictors of Parental Supportive Behavior in Parents of Girls

\begin{tabular}{|c|c|c|c|}
\hline & $B^{a}$ & $S E B^{b}$ & $\beta^{\mathrm{c}}$ \\
\hline Child Grade & -.041 & .018 & $-.114 *$ \\
\hline Free and reduced lunch eligible (SES) & -.118 & .079 & .085 \\
\hline Parent Physical Activity & .002 & .000 & $.303^{*}$ \\
\hline Parent Body Mass Index & .017 & .006 & $.153 *$ \\
\hline Parent Fruit/Vegetable servings & .036 & .021 & .094 \\
\hline Current smoker & .072 & .091 & .045 \\
\hline Constant & 2.564 & .201 & \\
\hline
\end{tabular}

Adjusted $\mathrm{R}^{2}=.138 . * \mathrm{p}<.05$

${ }^{\mathrm{a}}$ Unstandardized Beta; ${ }^{\mathrm{b}}$ Standard Error; ${ }^{\mathrm{c}}$ Standardized Beta; 
Table 2.6: Predictors of Parental Supportive Behavior in Parents of Boys

\begin{tabular}{|c|c|c|c|}
\hline & $B^{a}$ & $S E B^{b}$ & $\beta^{\mathrm{c}}$ \\
\hline Child Grade & -.027 & .019 & -.074 \\
\hline Free and reduced lunch eligible (SES) & -.075 & .074 & .056 \\
\hline Parent Physical Activity & .001 & .000 & $.287^{*}$ \\
\hline Parent Body Mass Index & -.002 & .005 & -.023 \\
\hline Parent Fruit/Vegetable servings & .025 & .021 & .065 \\
\hline Current smoker & -.091 & .080 & -.063 \\
\hline Constant & 3.356 & .181 & \\
\hline
\end{tabular}

Adjusted $\mathrm{R}^{2}=.09 . * \mathrm{p}<.05$

${ }^{\mathrm{a}}$ Unstandardized Beta; ${ }^{\mathrm{b}}$ Standard Error; ${ }^{\mathrm{c}}$ Standardized Beta; 


\subsection{Figures}

Figure 2.1: CARDIAC Survey Response Numbers for grades K, 2, \& 5
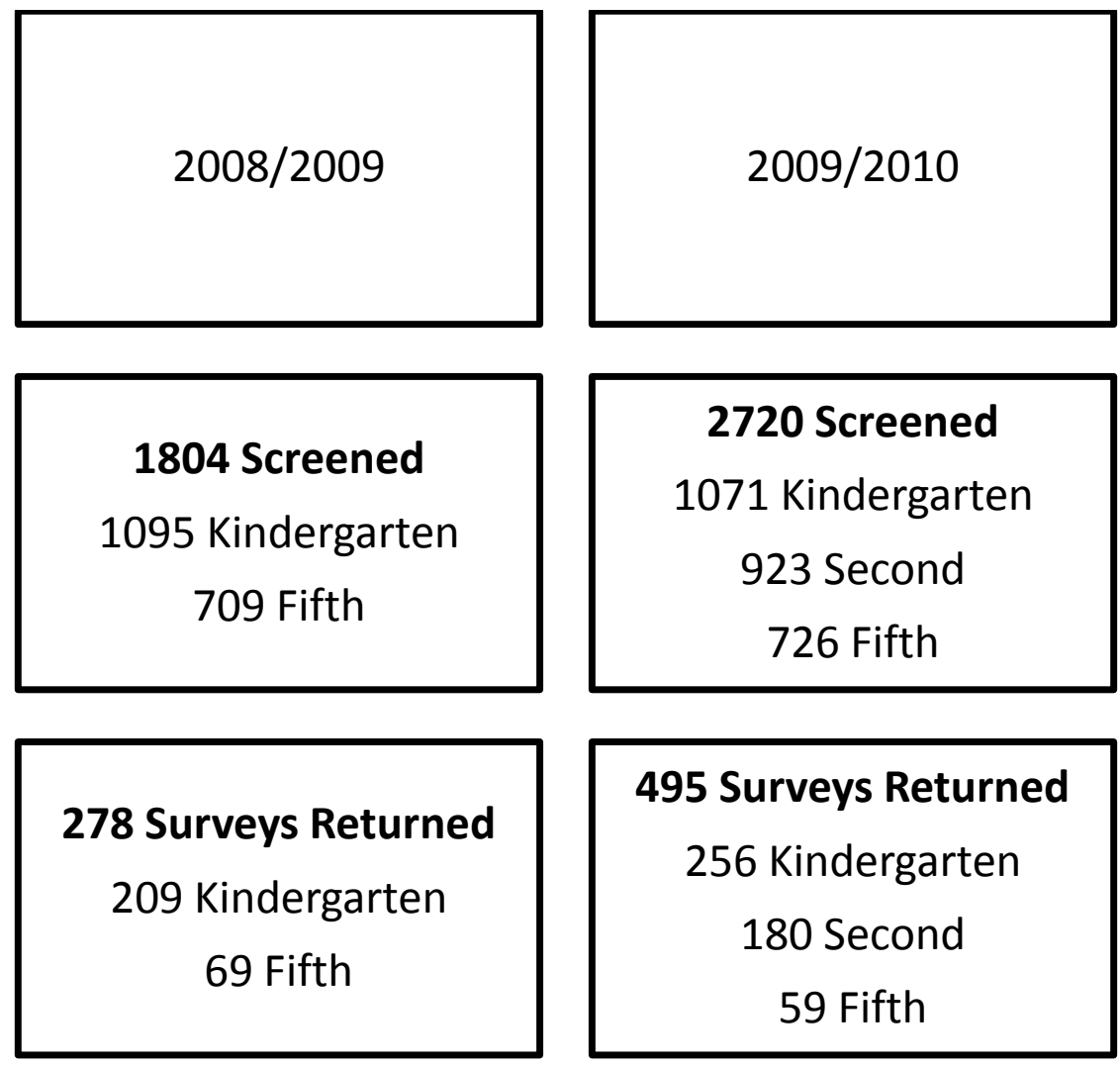

495 Surveys Returned

256 Kindergarten 180 Second 59 Fifth

$$
N=773
$$


Chapter 3 


\section{Chapter 3}

\subsection{Background}

The physical and psychological benefits of childhood physical activity are well documented. [19, 20] Specifically, childhood physical activity is associated with improved metabolic health including blood pressure, cholesterol/HDL ratio, triglycerides, and insulin resistance. [21] In overweight youth, it effectively prevents onset of type two diabetes mellitus [22] and is an instrumental component of obesity prevention efforts. [2-5] In adolescents, physical activity can have long-term impacts on adult health including decreased levels of sedentary activity, reduced breast cancer risk and improved bone health. [23] Psychologically, physical activity can lead to decreased anxiety, depression, social inhibition, [24] and improved social and physical self-perception. [25] Notably, these mental and emotional health benefits occur both in older childhood and adolescence. [24, 25] Additionally, there appear to be cognitive and education benefits to childhood physical activity. The majority of studies examining the relationship between physical activity, physical education, physical fitness and academic performance find a positive relationship. [28]

Although the benefits of physical activity are well known, only $34.7 \%$ of US adolescents met the recommended 60 minutes of physical activity per day [32] in 2007. [33] Furthermore, physical activity levels decline throughout childhood and adolescence. [34-36] There is some

evidence that this decline is greater for girls than it is for boys. [89] This decline coincides with increases in body mass index (BMI). [37] As a result, methods to curtail this decline are needed.

A consistent finding in physical activity research is that boys have higher levels of activity in childhood and adolescence than do girls. $[35,55]$ The cause of this disparity remains unclear, but it is likely due to complex interactions among the factors that influence gender 
development and physical activity. [38, 39, 42] Socialization views of gender development posit that individuals are treated differently based on gender. [40] Specifically, social learning theory describes learning as a process of modeling and reinforcement with individuals being positively reinforced for actions that are deemed gender-appropriate. [43] Since physical activity is deemed as a more masculine activity, [46] it is possible that boys are reinforced for physical activity and girls are not. Nonetheless, girls benefit from physical activity as boys do. [21, 25]

Parents are frequently the focus of exploration when examining child physical activity. Initially, the majority of studies focused on observational learning by examining the role of parental modeling of physical activity on child behavior. Collectively, these studies produced inconclusive findings. [55, 64] This led to exploration of the influence of parental supportive behavior. In contrast to the earlier work, these studies consistently demonstrated a strong positive relationship between child physical activity and parental support for child physical activity. [58, 64, 65] This concept is supported by social learning theory which posits that modeling can increase learning, while encouragement and support can reinforce physical activity and increase self-efficacy. [125]

Thus, while parents themselves may be inactive, they can still impact childhood physical activity by making efforts to be supportive of this behavior. This is vital to intervention programming to motivate parents with poor health to positively impact their child's health. Parental support encompasses emotional support, instrumental support, and parental involvement. [64] Instrumental support refers to facilitative behavior such as transportation. Emotional support includes encouragement and praise, and involvement includes active participation in physical activity with the child. All of these types of support have been found to positively correlate with child physical activity. [66-70] Coinciding with the gender disparity in 
levels of childhood physical activity, a gender discrepancy is also present in parental supportive behavior, with parents of boys reporting higher levels of support than parents of girls. [64, 67, 72] However, increased parental support in girls is related to increased levels of physical activity. [71, 73] Thus, to increase physical activity and eliminate this gender disparity, increasing parental support might be an effective avenue for intervention.

Unfortunately, the influence of parental supportive behavior for both genders decreases throughout adolescence as youth gain independence and peer influence is stronger. [64, 74] However, increased levels of supportive behavior in late childhood and early adolescence can have lasting impact on physical activity throughout the adolescent years. [76] It is therefore, essential that interventions find ways to increase parental supportive behavior in childhood when it has the greatest impact. Yet, very little is known about what factors influence parental supportive behavior and what subpopulations of children may have the low or high levels of parental support.

To begin examining the factors that influence parental supportive behavior for physical activity, it is helpful to identify the factors related to child physical activity. One factor is family composition; this includes the number of children, child gender, and the number of parents in the household. One study found that girls with at least one sibling had higher levels of moderate to vigorous physical activity than did only children. [86] This main effect was qualified by a significant interaction between presence of siblings and number of parents in the home. Girls from two parent homes with a sibling had increased levels of physical activity whereas girls from one parent homes did not have a significant increase in physical activity with the presence of a sibling. This study analyzed both presence of siblings and then, specifically, the presence of a brother. Boys with a brother in a two parent household did not have significantly higher levels 
of physical activity but boys in a single parent household had higher rates of physical activity with the presence of a brother. A study of adolescents in England found that having a sister was negatively related to weekend physical activity in boys. [87] These findings demonstrate that the presence and gender of siblings may influence children's physical activity. Number of parents in the home may also influence parental supportive behavior for physical activity. Sallis and colleagues found that boys had higher levels of physical activity in single parent homes. [66] Since there is an established relationship between both childhood physical activity and parental supportive behavior [58] and child physical activity and family composition, [86] it is important to explore the influence of family structure and child gender on parental supportive behavior. If specific family profiles can be identified, then these types of families can be targeted for intervention.

The purpose of this study was to examine the influence of family structure on parental supportive behavior utilizing cross-sectional data collected through the Coronary Artery Risk Detection in Appalachian Communities (CARDIAC) project. We hypothesized that family composition would influence parental supportive behavior. Based on previous findings that girls receive lower levels of support than do boys, $[64,67,72]$ we predicted that parents of boys would report higher levels of support than would parents of girls, and that parents with a higher percentage of female children would report lower levels of support. Due to previous research showing that more children in the home increases physical activity, [86] we hypothesized that total number of children in the home would positively influence parental supportive behavior and due to previous findings that boys from single parent homes are more active, we hypothesized that the total number of adults in the home would have a negative influence on parent support. Due to previous research showing that the influence of parent support decreases as children age, 
$[64,67]$ we predicted that levels of parental support would decrease with grade. Finally, we predicted that SES would be a positive predictor for parental supportive behavior due to previous research identifying a positive relationship between SES and physical activity. [100] SES and grade were included as covariates due to the established positive relationship between child physical activity and SES [64] and the negative relationship between parental supportive behavior and age. [126]

\subsection{Method}

Secondary data analysis was conducted with cross-sectional data collected through the CARDIAC project to explore the influence of family structure and child gender on parental supportive behavior. The CARDIAC project screens children in West Virginia for cardiovascular disease risk.

\subsubsection{Participants}

Participants were 741 parents of children in kindergarten, $2^{\text {nd }}$, and $5^{\text {th }}$ grade who were screened during the 2008/2009 and 2009/2010 school years in eight geographically dispersed counties in West Virginia (Braxton, Clay, Marshall, Mason, Monongalia, Pendleton, Taylor, and Lincoln). West Virginia, located in Appalachia, is a largely rural state with elevated rates of chronic disease and chronic disease risk [101] and high rates of poverty. [120] Children in select grades in each county were eligible for screening through the CARDIAC project. Parents were sent information through their child's school requesting consent for participation and to complete the first page of a screening form. Information on the screening form included child and family demographic data and family health history. Parents then returned the form to the child's school. On the day of the screening, the remainder of the screening form was completed by a member of the CARDIAC team and included markers of cardiovascular disease risk such as height, weight, 
and presence of acanthosis nigricans, a hyper pigmented skin in the base of the neck, axillae or groin typically associated with hyper insulinemia. Fifth graders received additional screening including a blood draw. For all children who were screened in the eight selected counties, a report was prepared with the findings from their screening and was sent to the parents along with a survey for additional research. In 2008/2009, the report was sent through the United States Postal Service and in 2009/2010 the report was sent home in a sealed envelope with the child through their school. Parents were asked to complete the survey and return it via an enclosed stamped, addressed envelope. For the 2008/2009 and 2009/2010 school years, 4,695 Kindergarten, second, and fifth graders completed the screening and were sent a packet with surveys (see figure I). A total of 773 parent surveys were completed for a response rate of 16.5\%. Data from grandparents, stepparents, and non-respondents $(\mathrm{N}=32)$ were eliminated due to confusion based on questions related to number, order, and gender of children. Additional information on the CARDIAC project has been published previously. [102-105] 
Figure 3.1: CARDIAC Survey Response Numbers for grades K, 2, \& 5
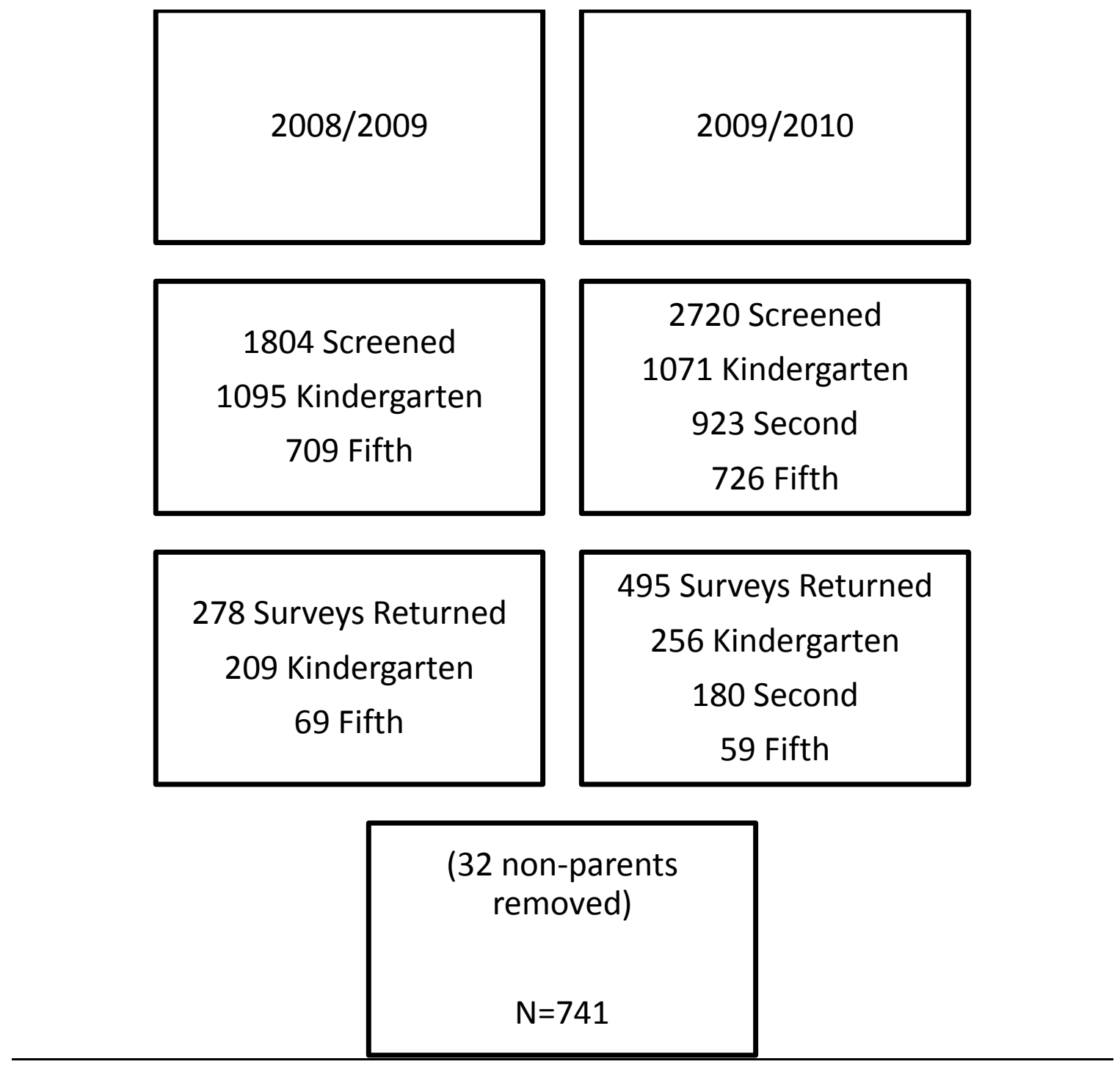

\subsubsection{Measures}

Parental Supportive Behavior A composite scale encompassing five supportive behaviors: transportation, encouragement, praise, watching, and participation was used to measure parental supportive behavior (See table 3.1). This scale is based on a scale initially developed for the Amherst Health and Activity Study. [90] Response options use a five point Likert-type scale and range from never (1) to daily (5). Internal reliability was calculated with Cronbach's alpha to be .71 in this sample. An average of the five questions was calculated to 
obtain a composite score ranging from 1-5. Participant scores were included if they completed at least three of the five questions.

\begin{tabular}{|l|l|}
\hline \multicolumn{2}{|l|}{ Table 3.1: Parental Supportive Behavior Scale } \\
\hline Construct & Question: Please indicate how often you: \\
\hline Transportation & Transport your child to a place to be physically active \\
\hline Encouragement & Encourage your child to be physically active \\
\hline Praise & Praise your child for being physically active \\
\hline Watching & Watch your child play sports or be physically active \\
\hline Participation & Take part in physical activity with your child \\
\hline Response Options: Never/Almost never (1); Monthly (2), Weekly (3), Almost Daily (4), Daily \\
(5)
\end{tabular}

Family Composition Family composition was measured by parent report of the number of male and female children in the household, as well as the number of adults, 18 years of age and older. The percentage of children who are female in the home was calculated by dividing the number of daughters by the total number of children (i.e. a family with 2 sons and 2 daughters $=.5 ; 1$ son and 3 daughters $=.75)$. Additionally, the gender of the child participant was identified. Due to elevated levels of kurtosis, the question assessing number of adults in the home was converted from a continuous to ordinal variable with options of one, two, or three or more. [127]

Demographic Measures Child participation in the free or reduced lunch program was used as a proxy for socio-economic status. [114] Initially 7\% of SES data was missing. The missing scores were then calculated based on household size and annual income to determine if 
they would qualify for free and reduced lunch based on Department of Education guidelines for 2009/2010[115] Missingness was reduced to $1 \%$. Three questions were used to measure annual income and household size: What is your approximate yearly household income? Participants had eight response options ranging from $<10,000$ to 100,000 or more. What are the ages of your children (18 and under) in your household (each response was converted to a one and them summed to obtain the total number of children in the household) and How many adults 19 and older live in your household? were added together to determine household size.

\subsubsection{Statistical Analysis}

Independent samples t-test was used to check for child gender differences in parental supportive behavior. Bivariate correlations were used to explore relationships between variables according to child gender. Child gender-specific regression models were run to assess the impact of family structure on parental supportive behavior. We controlled for SES and child grade. All analyses were conducted in PASW 18 (formerly SPSS). All data were checked for assumptions such as normality, linearity, homoscedasticity and outliers. Number of adults in the home had elevated kurtosis; and was therefore changed to a categorical variable with 1, 2, and 3 or more parents. No other transformations were necessary. 
3.3 Results

Table 3.2: Participant Demographics

\begin{tabular}{|c|c|c|c|}
\hline & $\begin{array}{c}\text { Combined } \\
\mathrm{N}(\%)\end{array}$ & $\begin{array}{l}\text { Girls } \\
\mathrm{N}(\%)\end{array}$ & $\begin{array}{l}\text { Boys } \\
\text { N (\%) }\end{array}$ \\
\hline $\mathrm{N}$ & 741 & 370 & 371 \\
\hline Mean Parent Age & 35.47 & 35.23 & 35.71 \\
\hline \multicolumn{4}{|l|}{ Who completed form } \\
\hline Mothers & $701(94.6 \%)$ & $353(95.4 \%)$ & $348(93.8 \%)$ \\
\hline Fathers & $40(5.4 \%)$ & $17(4.6 \%)$ & $23(6.2 \%)$ \\
\hline \multicolumn{4}{|l|}{ Grade } \\
\hline Kindergarten & $441(59.5 \%)$ & $206(55.7 \%)$ & $235(63.3 \%)$ \\
\hline Second & $173(23.3 \%)$ & $93(25.1 \%)$ & $80(21.6 \%)$ \\
\hline Fifth & $127(17.1 \%)$ & $71(19.2 \%)$ & $56(15.1 \%)$ \\
\hline \multicolumn{4}{|l|}{ Free or reduced lunch } \\
\hline Eligible (Lower SES) & $296(39.9 \%)$ & $147(39.7 \%)$ & $149(40.2 \%)$ \\
\hline Not Eligible (Higher SES) & $436(58.8 \%)$ & $217(58.6 \%)$ & $219(59.0 \%)$ \\
\hline \multicolumn{4}{|l|}{ N- Adults } \\
\hline 1 & $92(12.4 \%)$ & $44(11.9 \%)$ & $48(12.9 \%)$ \\
\hline 2 & $568(76.7 \%)$ & $285(77.0 \%)$ & $283(76.3 \%)$ \\
\hline$\geq 3$ & $61(8.2 \%)$ & $30(8.1 \%)$ & $31(8.4 \%)$ \\
\hline Mean N-Child & 2.19 & 2.18 & 2.20 \\
\hline Mean Female child \% & $48 \%$ & $73 \%$ & $22 \%$ \\
\hline Mean Parental Supportive Behavior & 3.71 & 3.64 & 3.77 \\
\hline
\end{tabular}

$\mathrm{N}=$ Number 
Participants were mostly mothers $(94.6 \%)$ and parents of kindergarteners $(59.5 \%)$. On average, their children were not eligible for free or reduced lunch $(58.8 \%)$ and families consisted of two parent homes (76.7\%). The mean number of children in the home was 2.19. Independent samples t-test showed that there was a significant difference in reported levels of parental supportive behavior scores between parents of boys $(\mathrm{M}=3.77, \mathrm{SD}=.66)$ and parents of girls $(\mathrm{M}=3.65, \mathrm{SD}=.67) ; \mathrm{t}(735)=-2.510, \mathrm{p}=.012$ with parents of boys reporting greater support.

When compared to a WV BRFSS data from 2009, [106] the study sample had a much higher percentage of parents who met the physical activity recommendations: $64.9 \%$ compared to $35.2 \%$. The study sample also had a higher percentage $(23.1 \%)$ of individuals consuming 5 or more fruits and vegetables per day compared to WV BRFSS (16.2\%). The study sample also had lower percentages of overweight $(28.1 \%)$ and obesity $(26.7 \%)$ when compared to the WV BRFSS: $35.8 \%$ and $31.7 \%$ respectively. The study sample was very similar to the WV BRFSS with $26.6 \%$ of the study sample reported being current smokers and $25.6 \%$ of the WV BRFSS classified as current smokers. (See table 3.3)

Table 3.3: Summary of health behaviors among the study sample and the WV BRFSS representative sample

\section{Study Sample WV(BRFSS 2009)}

\begin{tabular}{l|cc}
\hline Physical activity (percent meeting recommendations) & $64.9 \%$ & $35.2 \%$ \\
Obese (BMI $\geq 30$ ) & $26.7 \%$ & $31.7 \%$ \\
Overweight (BMI 25-29.99) & $28.1 \%$ & $35.8 \%$ \\
Current smokers & $26.6 \%$ & $25.6 \%$ \\
5 or more Fruits and Vegetables a day & $23.1 \%$ & $16.2 \%$ \\
\hline
\end{tabular}


Bivariate correlation and linear regression models were run for parents of boys and parents of girls separately to determine the relationship between variables and to assess the influence of grade, SES, total number of children, number of adults, and the percentage of female children on parental supportive behavior as the criterion variable. 
Table 3.4: Child gender-specific bivariate correlation with Bonferonni correction

\begin{tabular}{|c|c|c|c|c|c|c|c|c|c|c|c|c|}
\hline \multirow[b]{2}{*}{ Factors } & \multicolumn{6}{|c|}{ Parents of Girls } & \multicolumn{6}{|c|}{ Parents of Boys } \\
\hline & 1 & 2 & 3 & 4 & 5 & 6 & 1 & 2 & 3 & 4 & 5 & 6 \\
\hline 1. Grade & 1 & .029 & .047 & .056 & -.059 & -.108 & 1 & .050 & -.043 & -.064 & -.036 & -.126 \\
\hline 2. $\mathrm{FRL}^{\mathrm{a}}$ & & 1 & -.073 & -.010 & .068 & -.121 & & 1 & -.052 & .028 & .110 & -.031 \\
\hline 3. N-child ${ }^{\mathrm{b}}$ & & & 1 & $-.326 *$ & .127 & .134 & & & 1 & $.335 *$ & .062 & .031 \\
\hline 4. Female $\%^{\mathrm{c}}$ & & & & 1 & -.016 & -.091 & & & & 1 & .123 & -.034 \\
\hline 5. $\quad \mathrm{N}$-adult ${ }^{\mathrm{d}}$ & & & & & 1 & -.022 & & & & & 1 & -.058 \\
\hline 6. $\mathrm{PSB}^{\mathrm{e}}$ & & & & & & 1 & & & & & & 1 \\
\hline
\end{tabular}

$* \mathrm{p} \leq .002$

${ }^{\mathrm{a}}$ Free or reduced lunch eligibility; ${ }^{\mathrm{b}}$ Number of children in home; ${ }^{c}$ Percentage of female children in the home; ${ }^{\mathrm{d}}$ Number of adults in home; ${ }^{\mathrm{e}}$ Parental supportive behavior 
Bivariate correlations with Bonferroni correction shows that none of the variables had a significant association with parental supportive behavior in either parents of girls or parents of boys (See table 3.4). Child gender-specific standard linear regression models were conducted with parental supportive behavior as the criterion measure. Grade, SES, total number of adults, total number of children, and female child percentage served as predictors. All variables were entered into the model at the same time due to the exploratory nature of the research question. Assumptions such as normality, outliers, linearity, multicolinearity, and homoscedasticity were evaluated. All variables were in range and were not transformed (see table 3.5).

Linear regression analysis examining parents of female children resulted in a significant model. This model was significant $(\mathrm{F}(5,346)=4.251, p<.001)$ with an adjusted $\mathrm{R}^{2}$ of .044 . SES $t(346)=-2.514, p<.05$, grade $t(346)=-2.360, p<.05$ and total number of children $t(346)=$ $2.166, p<.05$ were significant predictors. Beta coefficients indicate that a one unit increase in SES will result in an estimated 194 decrease in parental supportive behavior and a one unit increase in grade will result in a .043 decrease in parental supportive behavior controlling for covariates. Additionally, a one unit increase in total number of children will result in a .101 increase in parental supportive behavior controlling for covariates.

For parents of boys, the model was not significant $(\mathrm{F}(5,349)=1.732, p>.05)$. Only grade $t(349)=-2.412, p<.05$ was a significant predictor. The model indicates that a one unit increase in grade will result in a .047 decrease in parental supportive behavior controlling for covariates (See table 3.5). 
Table 3.5: Predictors of Parental Supportive Behavior

\begin{tabular}{|c|c|c|c|c|c|c|}
\hline & \multicolumn{3}{|c|}{ Parents of boys } & \multicolumn{3}{|c|}{ Parents of girls } \\
\hline & $B^{a}$ & $S E B^{b}$ & $\beta^{\mathrm{c}}$ & $B^{a}$ & $S E B^{b}$ & $\beta^{\mathrm{c}}$ \\
\hline FRL $^{d}$ & -.033 & .072 & -.025 & -.181 & .072 & $-.132 *$ \\
\hline Grade & -.047 & .020 & $-.128 *$ & -.044 & .019 & $-.124 *$ \\
\hline N-Children & .037 & .041 & .051 & .101 & .047 & $.121 *$ \\
\hline N-Adults & -.080 & .076 & -.057 & -.053 & .078 & -.036 \\
\hline Female child $\%$ & -.134 & .144 & -.053 & -.135 & .140 & -.054 \\
\hline \multirow[t]{2}{*}{ Constant } & 3.982 & .199 & & 3.980 & .246 & \\
\hline & \multicolumn{3}{|c|}{ Adjusted $\mathrm{R}^{2}=.010 ; * \mathrm{p}<.05$} & \multicolumn{3}{|c|}{ Adjusted $\mathrm{R}^{2}=.044 ; * \mathrm{p}<.05$} \\
\hline
\end{tabular}

${ }^{a}$ Unstandardized Beta; ${ }^{b}$ Standard Error; ${ }^{c}$ Standardized Beta; ${ }^{d}$ Free or reduced lunch eligible

\subsection{Discussion}

Similar to previous findings, parents of girls reported lower levels of parental supportive behavior than did parents of boys. $[64,67,72]$ Overall the model did not account for much of the variance in parental supportive behavior for parents of either gender, however the model performed better in parents of girls. Our second hypothesis was not supported; the percentage of female children did not influence parental supportive behavior in either parents of boys or parents of girls. For girls, the total number of children in home is positive predictor of increased parental supportive behavior. This finding coincides with previous research documenting increases in physical activity for girls who have a sibling. [86] This finding however, was not present for parents of boys. Additionally total number of adults in the home did not influence parent support nor did it have a significant relationship with parent support. This may be influenced by the elevated number of two-adult households present in the study $(76.7 \%)$ 
restricting the range of responses and resulting in a loss of power and should be investigated further in future studies.

One surprising finding was that in parents of girls, an increase in SES resulted in a decrease in parental supportive behavior. This gender-specific finding warrants greater investigation in future studies. Perhaps parents with two jobs or higher demand jobs have less opportunity to support physical activity in their children. There are several possible reasons for this finding. Consistent with gender stereotypes for physical activity, parents may view that their support for girls' physical activity is less of a priority than it is for boys. Additionally, the potential lack of prioritization for girls' physical activity may result in less extended family and community support for girls' physical activity. This would make it more challenging for girls' parents to support physical activity when other demands arise, such as employment.

Our finding that parental support for physical activity is lower in families with higher SES raises questions about parent income and employment. Perhaps having one parent working in the home full time increases the opportunity for support for physical activity in girls' but would also decrease family income. It is possible in families where both parents are employed outside of the home, there is less time to support physical activity. However, this does not address the fact that this was a significant predictor only in parents of girls. Boys physical activity may be a priority in the majority of families due to male gender stereotypes associated with athleticism and sports, while girls' physical activity is not a stereotypical norm. Thus support for boys' physical activity would be maintained when both parents work outside the home while support for girls' physical activity may dwindle. Opportunities for girls' physical activity could also be more difficult to access, or require greater amounts of time from parents, than do opportunities for boys. This would occur if there are fewer opportunities for girls' activity and parents have to drive further 
distances to access available opportunities, increasing both the financial cost and the time required. In future studies it will also be important to explore other indicators of socioeconomic status such as parent education. Parent education could have a greater influence on support for child physical activity than annual income or free and reduced lunch status.

The only significant predictor found for boys was grade, which again coincides with previous knowledge that levels of both physical activity and parental supportive behavior decrease with age. [34-36, 64, 74] This predictor was also significant for parents of girls.

Although the model accounted for very little variance in parental supportive behavior for both parents of boy and parents of girls, findings suggest that parental supportive behavior for girls may be more influenced by family structure than is parental supportive behavior for boys. These findings imply that parental support for girls' physical activity should be prioritized in intervention efforts to increase girls' physical activity.

There are several limitations present in this study. It should be noted that the data was all self-reported and therefore subjective. Social desirability, the tendency of participants in selfreport surveys to portray themselves the way they believe they should be in light of societal norms, [123, 124] could also be influencing findings. Parents might report higher levels of parental support because they believe that is what they should be doing, or what society expects of good parents. When compared to the WV BRFSS, the study sample had a much higher percentage of individuals reporting meeting recommended levels of physical activity. The study sample also had a slightly higher percentage of individuals meeting recommendations for fruit and vegetable consumption and lower percentages of obese and overweight individuals. Unfortunately, we were not able to assess the influence of parent gender and interactions with child gender due to limited numbers of fathers completing the study (5.4\%). There are mixed 
findings on the impact of parental gender on parental support and childhood physical activity, [64] however having both parents would have provided a more complete picture of parental influences. Additionally, due to the low response rate, findings may not be generalizable. It is likely that non-respondents are different from respondents and could possibly have greater cardiovascular disease risk as has been found in other studies of non-respondents. [122] Factors potentially unaccounted for in this model would be influences based on sibling age and potential interactions with sibling age and gender. Also interactions between single parent homes and child gender may also provide greater information on the influences of family structure.

The finding that increases in the total number of children in the home predicts greater levels of parent support for child physical activity implies a need to target girls without siblings to increase parent support for physical activity. It is possible that girls' with a sibling experience increases in parent support for physical activity because they benefit from support that is provided to their sibling. This has been true in other studies where presence of a sibling increases physical activity in girls. [86, 87] Additionally further research on single parent homes and the influence of this on physical activity could also inform interventions. A single parent home could negatively impact parent support due to the fact that the single parent is fulfilling all roles and responsibilities in child rearing including financial responsibilities and would therefore have less time to support physical activity. Therefore more research is needed to determine the influence of single parenthood on parent support for physical activity. 
Chapter 4 


\section{Chapter 4}

\section{Parental support for physical activity in rural and non rural boys and girls}

\subsection{Background}

Health is influenced by multiple factors including geographic location. Rural areas are often characterized by health disparities including increased rates of chronic disease. [128] Rural areas also have higher rates of obesity and inactivity when compared to urban. [79, 80] Availability of resources and opportunity for health promotion, such as physical activity, can be much lower in rural areas. [129] Physical aspects of the rural environment that may be challenging for physical activity include lack of public transportation and limitations in the built environment, such as lack of sidewalks and parks, and lack of physical activity programming. [59] The lack of such resources can impede physical activity, as improved access to programs and facilities is positively associated with increased physical activity. [58]

Findings on childhood physical activity in rural populations are varied. Some studies have identified differences between rural and urban children, with rural children having higher rates of inactivity. [130, 131] In contrast, other studies have found no significant differences between rural and urban youth in inactivity. [60, 132, 133] A comparison of rural and urban youth in Canada found differences in active transport to school and physical education opportunities. [61] A study conducted in a Midwestern state in the U.S. found increased levels of obesity in rural youth, and decreased levels of physical activity among urban youth when both were compared to a small city population. [62] These inconsistencies may be attributable to SES, as there is an established relationship between barriers to childhood physical activity and parent income. [134] 
Increasing childhood physical activity in rural areas could be instrumental in decreasing health disparities in these areas due to the known benefits of physical activity. These benefits include improved metabolic health, obesity prevention, [2-5] and reduced disease risk. [12-17] Mental and emotional health benefits of childhood physical activity include lower levels of anxiety/depression and social inhibition, [24] and improved self-perception. [25] Cognitively, academic performance also has been found to have a positive relationship with physical activity, physical education, and fitness. [28, 29] These benefits not only improve health in childhood, but physical activity can have a lasting positive impact that extends into adulthood with decreased risk of cancer, decreases in sedentary behavior, and improved bone health. [23]

A consistent finding in physical activity research is that girls are less active than are boys, across all ages in childhood and adolescence. $[35,55]$ The causes of this disparity are multifaceted and complicated, and likely due to an interaction of biological and environmental factors. [38, 39] Gender socialization may reduce the level of physical activity in girls. According to Social Learning Theory, children learn through modeling and reinforcement. [43] Children are reinforced for acting in ways appropriate to their gender. [40] Since physical activity and sport has been historically seen as masculine behavior, [46] it is likely that girls receive lower levels of support for physical activity and that this type of behavior is reinforced less than it is in boys. Since girls benefit from physical activity as do boys, [21, 25] it is essential to identify gender-specific risk factors for physical inactivity so that efforts can be made to intervene to increase physical activity levels for both genders.

In addition to gender and rurality, parental influence on child physical activity has been researched in efforts to identify potential avenues for intervention. Research has consistently found a positive relationship between childhood physical activity and parental supportive 
behavior for childhood physical activity. [58, 64, 65] Parental supportive behavior encompasses several behaviors including emotional, participatory, and instrumental support. [64] Emotional support, including encouragement and praise is a positive correlate for child physical activity. $[67,69,70]$ Transportation is an example of instrumental support where parents actively aid children in being active. This also has a positive relationship with childhood physical activity. [66-68] Finally, parental involvement or participation in physical activity with their child also increases childhood physical activity. [66] Similar to the overall gender disparity in childhood physical activity, this disparity is also present in levels of parental supportive behavior, with boys receiving greater levels of support than do girls. [64, 67, 72] However, an increased level of parental support coincides with increased rates of physical activity in girls. [71, 73] This suggests that targeting parents of girls with interventions to increase support could have a positive impact on physical activity and health in girls.

The influence of parental supportive behavior on child physical activity appears to lessen as children grow and mature. [64, 74] Therefore, it would be advantageous to target parental support in childhood when parent support for physical activity has the greatest influence and could possibly impact the decline of physical activity in adolescence. Dowda and colleagues found that lower levels of parental support for girls' in junior high led to a sharper decline of physical activity by the twelfth grade. [76]

Previous research suggests that there is a positive relationship between socioeconomic status (SES) and child physical activity. $[64,100]$ This may be due to the increase in availability of physical activity resources and equipment that would likely come with increased financial resources. Additionally, parents with higher SES may be more educated about or aware of the benefits of child physical activity. Components of parental support would also be influenced by 
financial resources such as transportation. Previous research has also identified a decrease in parental support as children age. [126]

Differences in parent support for child activity by rural location are currently unknown. However, due to the previously mentioned health disparities in rural areas such as obesity [135] and inactivity, $[130,131]$ it is possible that rates of parental support for physical activity could be lower in rural areas. The purpose of this study was to identify differences in parental supportive behavior for boys and girls in rural and non-rural areas. If parents in rural areas have lower levels of supportive behavior they could be targeted in interventions specific to increasing parental support for child physical activity, and interventions could be modified so that they are tailored for rural areas. The hypotheses were that levels of parental supportive behavior for child physical activity would be higher in non-rural areas and that parental supportive behavior would be lower in parents of girls than it was in parents of boys. The hypotheses were tested with cross-sectional data collected through the Coronary Artery Risk Detection in Appalachian Communities (CARDIAC) initiative. This initiative provides screening for coronary artery disease among children in West Virginia.

\subsection{Method}

\subsubsection{Participants}

The study sample consisted of parents of kindergarten, $2^{\text {nd }}$, and $5^{\text {th }}$ grade students who completed both screening and surveys as part of the CARDIAC project in eight counties (Braxton, Clay, Marshall, Mason, Monongalia, Pendleton, Taylor, and Lincoln) in West Virginia in the 2008/2009 and 2009/2010 school years. A largely rural state, West Virginia has elevated rates of health risk behavior and chronic disease $[101,120]$ and an above average number of families and individuals living below the poverty line. [120] In each of these counties all 
students in select grades are eligible to participate in a screening for coronary artery disease risk through the CARDIAC project. While screening occurs state-wide, these counties were selected for additional research due to geographical dispersion and logistically strong coordinators. For both school years, parents received a consent and screening form through the schools, sent home with their child. Parents who chose to participate signed the consent, and completed a portion of the screening form detailing their child's and family health history. Parents then returned the form to their child's school through their child. On the day of the screening, the remainder of the screening form was completed by a CARDIAC team member and detailed height, weight, and the presence of acanthosis nigricans. AN, found in the skin on the base of the neck, axillae or groin is a hyper pigmentation typically associated with hyper insulinemia. Fifth graders have additional screening including blood pressure, cholesterol, and triglycerides. Findings from the screening were then compiled into a summary report for parents and sent to the home along with a survey for parents and a survey for older children to complete. In 2008/2009 parents were mailed findings and the survey(s) through the United States Postal Service and in 2009/2010 findings and survey(s) were sent home from the school with the child. While the methods and timing of delivery were different between screening years, there was no significant difference in parental supportive behavior between years. For the years combined 4,695 Kindergarten, $2^{\text {nd }}$, and $5^{\text {th }}$ graders completed the screening and were sent surveys. A total of 773 parent surveys were completed for a response rate of $16.5 \%$ (see Figure I). For further information on the CARDIAC initiative please see previous publications. [102-105] 
Figure 4.1: CARDIAC Survey Response Numbers for grades K, 2, \& 5
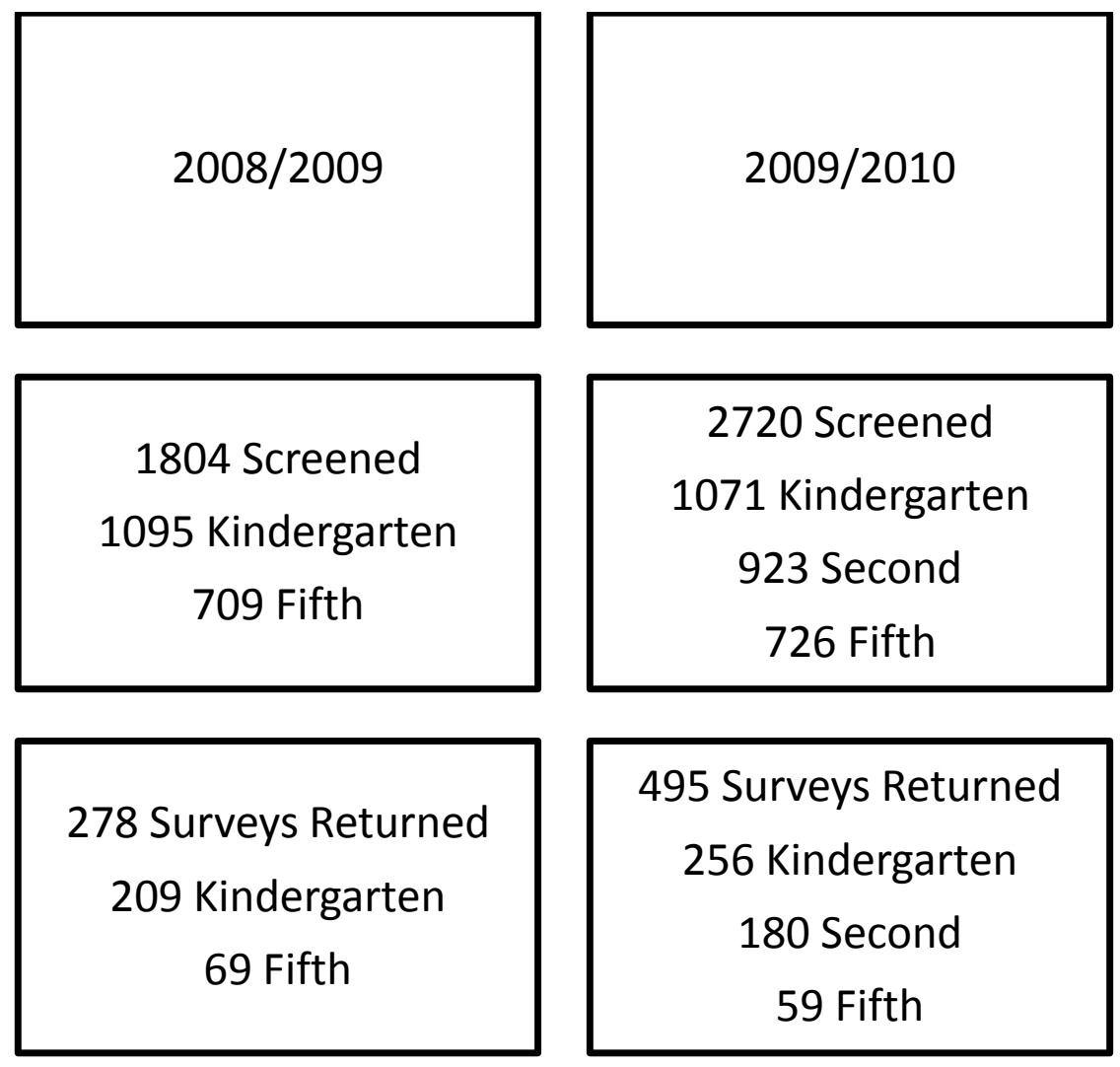

$N=773$

\subsubsection{Measures}

Parental Supportive Behavior Questions assessing five supportive behaviors (transportation, encouragement, praise, watching, and participation) were combined to create a composite scale to measure parental supportive behavior (See table 4.1). [90] Response options ranged from never (1) to daily (5) on a five point Likert-type scale. Cronbach's alpha was used to measure internal reliability and was .71 in this sample. An average of the five questions was 
calculated to obtain a score ranging from 1-5. If participants completed at least three of the questions their score was included in analysis.

\begin{tabular}{|l|l|}
\hline \multicolumn{2}{|l|}{ Table 4.1: Parental Supportive Behavior Scale } \\
\hline Construct & Question: Please indicate how often you: \\
\hline Transportation & Transport your child to a place to be physically active \\
\hline Encouragement & Encourage your child to be physically active \\
\hline Praise & Praise your child for being physically active \\
\hline Watching & Watch your child play sports or be physically active \\
\hline Participation & Take part in physical activity with your child \\
\hline Response Options: Never/Almost never (1); Monthly (2), Weekly (3), Almost Daily (4), Daily \\
(5)
\end{tabular}

Rurality To evaluate the influence of rural location on parental supportive behavior, Rural Urban Commuting Area Codes (RUCA) were utilized to classify individuals based on their residential zip code. RUCA is a commonly used $[136,137]$ sub-county rural/urban classification based on population density and population commuting patterns. There are 33 classifications, which are typically divided into 2-4 groups, ranging from rural, small town, large town, and urban. [138] For the purposes of this study, a dichotomous rural/non-rural measure was used.

Demographic Measures Participation in the free or reduced lunch program was used as a proxy for socio-economic status. [114] Seven percent of parent data was initially missing. Utilizing responses on household size and annual income, missing scores were calculated to determine if they would qualify for free or reduced lunch based on Department of Education 
guidelines for 2009/2010. [115] This reduced missingness to 1\%. Child gender was also used in analysis.

Statistical Method Data analysis consisted of descriptive statistics including frequencies, and percentages. Group differences in parental supportive behavior were analyzed with a 2 (gender) x 2 (rurality) factorial ANCOVA controlling for socio-economic status and grade as covariates. We tested for main effects for gender and rurality and also for a gender $\mathrm{x}$ rurality interaction effect. Participants were classified into two groups, either rural or non-rural based on previous analysis with RUCA data. $[138,139]$ RUCA is a sub-county measure of rurality based on zip codes. All variables had missing data $<5 \%$. Therefore, mean substitution or imputation was unnecessary. [116]

\subsection{Results}

A total of 773 parent surveys were completed, 387 were parents of girls and 386 were parents of boys. The majority of completed surveys were by parents of Kindergarteners (60.2\%), non rural (60.3\%), and not eligible for free or reduced lunch (high SES) (57.4\%) (See table 4.2). 
Table 4.2: Participant Demographics

\begin{tabular}{|c|c|c|c|}
\hline & Combined & Girls & Boys \\
& $\mathrm{N}(\%)$ & $\mathrm{N}(\%)$ & $\mathrm{N}(\%)$ \\
\hline $\mathrm{N}$ & 773 & 387 & 386 \\
\hline Grade & & & $248(64.2 \%)$ \\
\hline Kindergarten & $465(60.2 \%)$ & $217(56.1 \%)$ & $82(21.2 \%)$ \\
\hline Second & $180(23.3 \%)$ & $98(25.3 \%)$ & $56(14.5 \%)$ \\
\hline Fifth & $128(16.6 \%)$ & $72(18.6 \%)$ & $144(37.3 \%)$ \\
\hline Rurality & & & $228(59.1 \%)$ \\
\hline Rural & $293(37.9 \%)$ & $142(36.7 \%)$ & \\
\hline Non-rural & $466(60.3)$ & $230(59.4 \%)$ & 3.77 \\
\hline Free or reduced lunch & & & \\
\hline Eligible (Lower SES) & $320(41.4 \%)$ & $161(41.6 \%)$ & $159(41.2 \%)$ \\
\hline Not Eligible (Higher SES) & $444(57.4 \%)$ & $220(56.8 \%)$ & $224(58.0 \%)$ \\
\hline Mean Parental Supportive \\
Behavior
\end{tabular}

When compared to WV BRFSS data from 2009, the study sample had a much higher percentage (64.3\%) of individuals meeting physical activity recommendations (30+ minutes of moderate physical activity on 5 or more days per week or $20+$ minutes of vigorous activity on 3 or more days per week). The study sample also had a lower percentage of overweight (27.9\%) and obese (27.0\%) individuals compared to the WV BRFSS: $35.8 \%$ and $31.7 \%$ respectively. A higher percentage of the study sample (22.8\%) reported consuming 5 or more fruits and 
vegetables a day compared to the WV BRFSS (16.2\%). There was, however, a greater percentage (27.8) of current smokers in the study sample when compared to the WV BRFSS (25.6\%). (See table 2.3)

Table 4.3: Summary of health behaviors among the study sample and the WV BRFSS representative sample

\begin{tabular}{l|cc}
\hline \multicolumn{1}{l}{ Study Sample } & WV(BRFSS 2009) \\
\hline Physical activity (percent meeting recommendations) & $64.3 \%$ & $35.2 \%$ \\
Obese (BMI $\geq 30)$ & $27.0 \%$ & $31.7 \%$ \\
Overweight (BMI 25-29.99) & $27.9 \%$ & $35.8 \%$ \\
Current smokers & $27.8 \%$ & $25.6 \%$ \\
5 or more Fruits and Vegetables a day & $22.8 \%$ & $16.2 \%$ \\
\hline
\end{tabular}

A 2 (gender) x 2 (rurality) factorial ANCOVA was used to measure group differences in parental supportive behavior. Grade and SES were controlled for as covariates. The model was significant $F(5,738)=4.012, p<.05$, with an adjusted $\mathrm{R}^{2}$ of .02 . There was a significant main effect of gender on parental supportive behavior $\mathrm{F}(1,738)=5.736, p<.05$, after controlling for grade and SES. The covariate, grade, was significantly related to parental supportive behavior, $\mathrm{F}(1,738)=9.322, p<.05$. Rurality and SES were not significant. (See Tables 4.4 and 4.5 and Figure 4.1) 
Table 4.4: Rural and Non Rural Mean Parental Supportive Behavior Scores and Standard Deviations by Child Gender

\begin{tabular}{ccccc}
\hline & \multicolumn{2}{c}{ Rural } & \multicolumn{3}{c}{ Non-rural } \\
\cline { 2 - 5 } & $\underline{\mathrm{M}}^{\mathrm{a}}$ & $\underline{\mathrm{SD}}^{\mathrm{b}}$ & $\underline{\mathrm{M}}$ & $\underline{\mathrm{SD}}$ \\
\hline Parents of Girls & 3.67 & .66 & .61 & .70 \\
Low SES & 3.67 & .68 & 3.76 & .76 \\
High SES & 3.68 & .65 & 3.52 & .65 \\
Kindergarten & 3.75 & .66 & 3.72 & .65 \\
Second Grade & 3.53 & .70 & 3.41 & .76 \\
Fifth Grade & 3.62 & .62 & 3.57 & .66 \\
Parents of Boys & 3.80 & .66 & 3.74 & .67 \\
Low SES & 3.80 & .73 & 3.76 & .71 \\
High SES & 3.80 & .59 & 3.73 & .64 \\
Kindergarten & 3.83 & .62 & 3.84 & .66 \\
Second Grade & 3.78 & .67 & 3.56 & .70 \\
Fifth Grade & 3.70 & .76 & 3.60 & .58 \\
\hline
\end{tabular}

${ }^{\mathrm{a}}$ Mean; ${ }^{\mathrm{b}}$ Standard deviation 
Table 4.5: Analysis of Covariance of Parental Supportive Behavior Scores

\begin{tabular}{lcccc}
\hline & $\underline{\mathrm{Df}}^{\mathrm{a}}$ & $\underline{\mathrm{SS}}^{\mathrm{b}}$ & $\underline{\mathrm{MS}}^{\mathrm{c}}$ & $\underline{\mathrm{F}}^{\mathrm{d}}$ \\
\hline SES & 1 & .827 & .827 & 1.841 \\
Grade & 1 & 4.188 & 4.188 & $\mathbf{9 . 3 2 2 * *}$ \\
Rurality & 1 & .519 & .519 & 1.155 \\
Child Gender & 1 & 2.577 & 2.577 & $\mathbf{5 . 7 3 6 *}$ \\
Rurality $\mathrm{x}$ & 1 & .001 & .001 & .002 \\
Child Gender & & & & \\
\hline${ }^{*} \mathrm{p}<.05 . * * \mathrm{p}<.01$. & & & & \\
\hline
\end{tabular}

${ }^{\mathrm{a}}$ Degrees of freedom; ${ }^{\mathrm{b}}$ Sum of squares; ${ }^{\mathrm{c}}$ Mean square; ${ }^{\mathrm{d}} \mathrm{F}-$ ratio

Figure 4.1: Parental Supportive Behavior in Parents of Boys and Girls in Rural and Non-rural areas

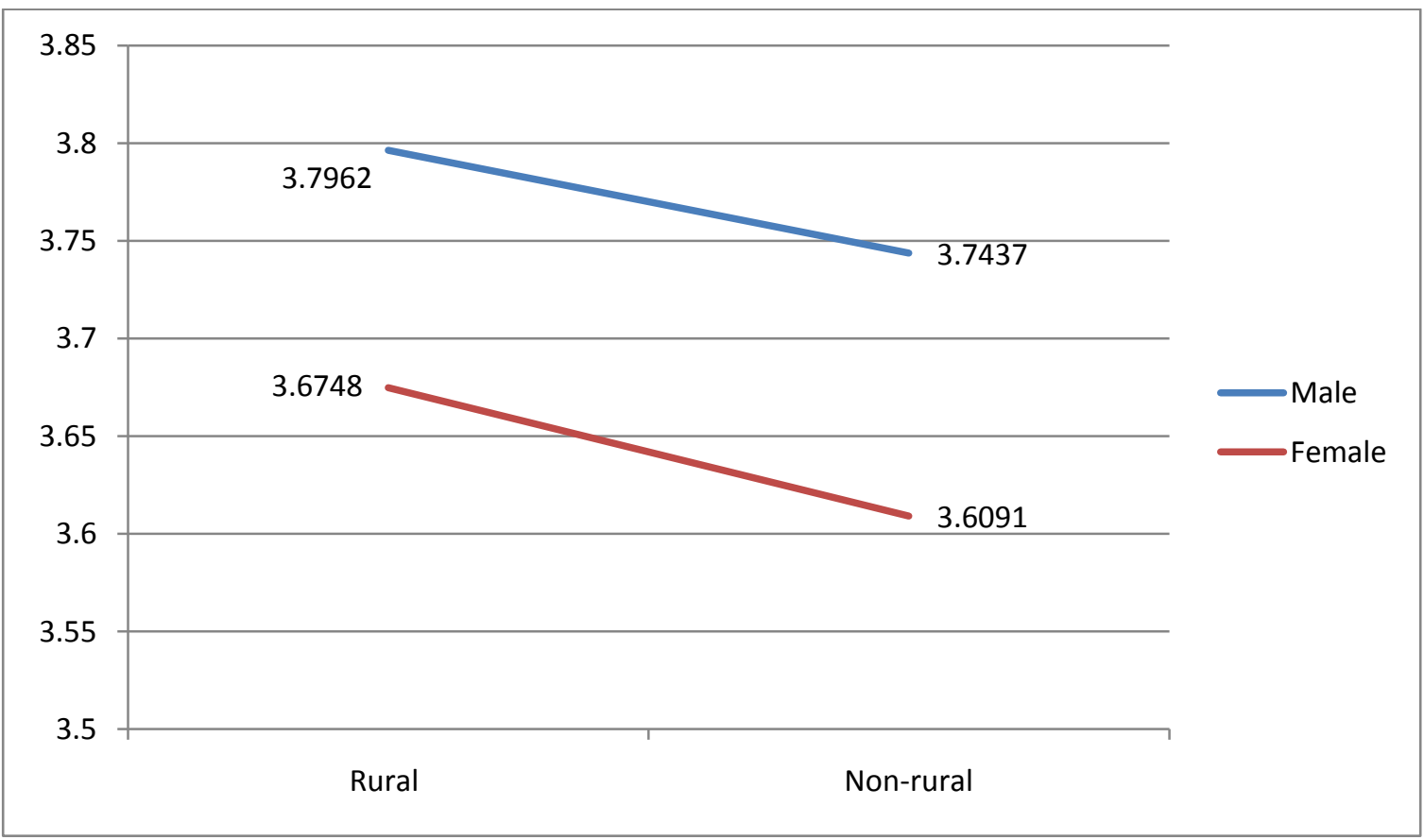

- Free and reduced lunch status and grade were included as covariates 


\subsection{Discussion}

This study explored group differences in parental supportive behavior for child physical activity between rural and non rural parents of boys and girls. Similar to previous findings, there was a main effect for gender with parents of girls providing less support than did parents of boys. $[64,67,72]$ This finding was significant while controlling for free and reduced lunch eligibility (SES) and grade as covariates. Also similar to other findings grade was a significant covariate, [140] with levels of parental support decreasing as grade increased. While not significant, parents in rural areas did report higher levels of support for childhood physical activity for both genders. This is encouraging: if parents in rural areas are more supportive this may protect children from chronic diseases that we know are higher in rural areas. [79, 80, 128] Perhaps due to these disparities parents are becoming more aware of the importance of encouraging physical activity. This was unexpected and leads to several questions about the rural environment and how it influences parent and family interaction.

Factors that could be influencing elevated support in rural areas are historical roots grounded in manual labor and farming. $[139,141]$ While this level of physical fitness might no longer be required, the concept that women had to be more physically active to contribute may still exist and thus physical activity in girls could be more supported in rural areas. Some might argue that rural culture is one of increased social support in general with elevated levels of social capital. [142] This might increase the likelihood that parents would have a support system in place to assist them in supporting child physical activity. Even if this is the case however, our study found that girls in rural areas still received lower levels of support than did boys. Therefore, it could be possible that boys' physical activity is seen as a higher priority than girls' physical activity both by parents and by the community. 
There are several limitations in this study that should be noted. The measure of rurality was based on a community-level variable and parental supportive behavior is an individual level variable, there is some risk of ecological fallacy and non-independence of data. This project used cross-sectional data, therefore causality cannot be determined. All parent data is selfreported, which is subject to bias. A particular concern is social desirability bias. Social desirability or the tendency to respond in a manner that portrays ones perception of societal norms, $[123,124]$ as opposed to personal behavior, can be a significant problem in self-report data. Additionally, while the sample is drawn from West Virginia, it does not represent the entire state of West Virginia and may not be generalizable. There is a low response rate, which also makes generalization difficult. All parents granted active consent for participation in screening, which could make them different from parents who did not grant consent. Parents who grant consent for the screening may be different from those who do not and among those screened only a small percentage completed the survey. Thus, parents who completed the survey may be very different from parents who did not consent. Other researchers have found that nonrespondents on a mail survey had higher rates of smoking than did individuals who completed a survey exploring cardiovascular disease risk. [122] As this survey assesses similar behaviors it likely that our study sample also has lower cardiovascular disease risk. As shown in table 4.3 the sample appears to be somewhat healthier than the representative WV BRFSS sample, particularly when it comes to physical activity. Therefore it is likely that this sample places a higher priority on health and health behaviors. Due to a paucity of data from fathers, the influence of parent gender could not be explored. It will be important to identify support from fathers in future studies due to the important role that fathers play on physical activity development. [143-145] Finally, while we are measuring rural and urban areas, it should be 
noted that the entire sample is from central Appalachia and our non-rural sample could be considered rural by some. Thus it will be important to conduct this study in a different population to determine differences by geographical region and how geographic region may interact with other factors. 
Chapter 5 


\section{Chapter 5}

\subsection{Summary}

The main objective of this project was to explore factors that may influence parental supportive behavior using multiple levels from the Social Ecological Model. Previous research has found that parent support for child physical activity has a positive relationship with child physical activity. $[58,64,65]$ Further, it has been shown that boys are more active than girls and more likely to receive higher levels of support for physical activity. [64, 67, 72] These findings led to expert recommendations to develop interventions to increase parent support for child physical activity, particularly for girls. [83] Very little is known about factors that influence parental supportive behavior or what segments of the population might be at risk of lower levels of parental support. To develop successful child physical activity interventions, it is important to identify specific factors that influence parental support for child physical activity. Identifying specific groups at risk for lower levels of support could identify populations for targeted interventions. This project sought to address these gaps by exploring influences on parental supportive behavior for child physical activity at three separate levels of the Social Ecological Model: individual (health behavior), interpersonal (family composition), and community (rurality).

Chapter 2 detailed the influence of parent health risk behavior (individual level) on parent support for physical activity in boys and girls. This study found that parent physical activity in both parents of boys and parents of girls was a positive predictor of parent support. This study also found that grade was a negative predictor of parent support in parents of girls. This is important due to decreases in physical activity as girls' age. [34,36] Certain factors that might also decrease physical activity, such as early physical maturation in girls $[118,119]$ could 
compound decreases in physical activity that occur naturally as girls age. This indicates a need for targeted research and potentially an intervention to increase parent support for physical activity in girls who mature early. The unexpected finding that parent BMI was a positive predictor of parent support for physical activity for parents of girls was of particular interest. Parents who are overweight or obese might be more likely to encourage physical activity in their children in an effort to ensure that their daughters will have better health and physical appearance than they do. This might be particularly true in mothers, which were the majority of our study sample. Previous studies found that overweight mothers of daughters were more likely to monitor their child's diet and have more restrictive feeding patterns. [117] Additionally women in our culture have increased pressure and body image issues regarding weight and are more likely to consider themselves overweight. [121] Therefore weight issues and concerns related to the female gender could influence parent practices regarding factors contributing to obesity such as girls' physical activity.

Chapter 3 detailed a study examining the influence of family structure (interpersonal level) on parent support for physical activity parents of boys and girls. Specifically, the influence of number of children in the home, number of parents in the home, and the percentage of female children in the home were examined in child-gender specific regression models. Grade and SES were included as covariates. The only significant predictor for parents of boys was grade. However in parents of girls, grade, free and reduced lunch eligibility (SES) and total number of children were significant predictors of parental supportive behavior. More children in the home resulted in higher levels of parental supportive behavior for girls. Consistently, Bagley and colleagues found that girls without siblings had lower levels of physical activity. [86] This implies a need to increase research and intervention with girls without siblings to increase 
support for physical activity. Another surprising finding was that higher SES resulted in lower levels of parental supportive behavior in girls. One potential influence could be the presence of one parent working only in the home resulting in an increase in time to provide support, but a decrease in annual income. Perhaps in families where two parents are employed there is less time to provide support for physical activity. Nonetheless, this does not explain why this was only significant in parents of girls. It is possible that boys always receive support due to cultural stereotypes associated with males and physical activity and sports. However girls' physical activity is not so culturally prescribed and thus becomes less of a priority when parents have other time obligations. Additionally since in WV there are fewer job opportunities and higher rates of unemployment, it could be that some parents who have a higher level of education are unable to find employment. Therefore additional measures of SES should be used in the future to determine the role of parent education on support for physical activity.

Finally, Chapter 4 describes a comparison of parental support for boys and girls in rural and non-rural communities (community level) in West Virginia. A significant difference was found between levels of support between parents of boys and parents of girls, however there was no significant difference between rural and non-rural parents. While not statistically significant, rural parents did appear to offer higher levels of support. Further research is needed to verify this. Potential factors related to this finding of higher rates of support for physical activity in rural areas could be rural roots grounded in manual labor and farming. $[139,141]$ This lifestyle would have made it necessary for all to be more physically active and therefore girls in rural areas might experience some lingering effects of these beliefs compared to their non-rural counterparts. Rural areas may offer greater social support in general due to elevated levels of social capital. [142] Thus the community may be more able to support parents who are trying to 
support their children. However in rural areas, boys still experienced higher rates of parent support for physical activity than did girls. It could be possible that boys' physical activity is a higher priority than girls' physical activity and is therefore supported by both the community and parents at higher levels. An unknown factor in this study is the role of traditional beliefs and stereotypes on parent behavior. It could be that more traditional views would result in decreased levels of support for girls' physical activity.

\subsection{Significance}

The long term goal of this 3-study project was to inform parental interventions that promote physical activity in their children. A first step to achieve this goal is to identify what factors influence parental supportive behavior so that parental interventions can include necessary content and target groups and individuals appropriately. These findings support this goal by identifying predictors that influence parent support for physical activity, particularly in parents of girls. This project is significant for several reasons. The first is that these questions have not been previously addressed in this manner or in this population. By using the Social Ecological Model, we were able to examine influences on parental support at individual, interpersonal, and community levels. Additionally several interesting differences were found in parental support between parents of girls and parents of boys. Due to the known gender disparity in child and adolescent physical activity, this information can inform prevention and intervention efforts. Parents of girls did report lower levels of support and parental BMI, SES, and total number of children in the home appears to have an influence on support in parents of girls, but not in parents of boys. While we don't know why, it could be that parent support for boys' physical activity is more of a priority than it is in parents of girls. This could be influenced by culturally prescribed stereotypes which emphasize physical activity and sports behavior in males, 
but not as much in females. Therefore support for girls' activity experiences greater variability because it is not seen as universally important. Consistently, it is also possible that factors in the community could be more supportive of physical activity for boys and therefore it is easier for parents to support physical activity in boys. This could be particularly true if there are more facilities and programs for boys than there are for girls, or if activities that would be traditionally considered male (i.e. t-ball) are less expensive than physical activity options that would be considered female (i.e. dance class). If parents are unable to access programs for their child's physical activity or if they lack the resources, they may be unlikely to encourage this activity if they know they cannot provide it. Finally, this project leads to additional research questions regarding the role of parent gender, family structure, and rurality in parent support for child activity.

\subsection{Strengths and Limitations}

Strengths of this project include the innovative approach and utilization of the Social Ecological Model. It is the first known project to examine influences on parental support for child physical activity at multiple levels. Moreover, while the relationship between parental support and child physical activity is well documented, [58, 64, 83] few previous studies have examined parental supportive behavior as the primary outcome.

There are several limitations that should be noted. This project used cross-sectional data, therefore causality cannot be determined. Second, all parent data was self-reported, which is subject to social desirability bias, i.e., parents' wanting to present themselves according to societal norms as opposed to their actual behavior. $[123,124]$ Thus parents may report higher levels of supportive behavior if that is what they feel society expects of them. Additionally, while the sample is drawn from West Virginia, it does not necessarily represent the entire state of 
West Virginia and may not be generalizable to the entire state or to other rural populations. Comparison with the WV BRFSS data from 2009 found that the study sample had almost two thirds of individuals reporting meeting physical activity recommendations compared to roughly one third in the BRFSS sample. Additionally, the study sample had a higher percentage of respondents meeting recommended levels of fruit and vegetable consumption. The study sample also had lower percentages of overweight and obese individuals. While previous research has determined that the CARDIAC Project's fifth grade screening population is representative of the state rates of childhood overweight and obesity, [146] comparison of child BMI percentile screening data for participants who completed and returned the survey $(\mathrm{M}=65.11, \mathrm{SD}=27.1)$ and those who did not $(M=69.02, \mathrm{SD}=27.71)$ showed that those who did not complete the survey had children with significantly higher BMI $\mathrm{t}(4517)=-3.584, \mathrm{p}=.001$. Perhaps parents who did not complete the survey do not prioritize health behavior and therefore are less interested in participating in this type of research. Regardless of the cause, this implies that the participants who completed the survey are different from those who did not. Moreover, there is a low response rate, which also makes generalization difficult. For children to participate in the screening, parents granted active consent, then among those with active consent only $16.5 \%$ completed and returned the survey. It is very likely that they are significantly different from parents who did not complete the survey and also parents who did not consent for screening. There is very little data on fathers; therefore the impact of parent gender cannot be explored. Previous research identifies that fathers are a very important influence on boys' and girls' physical activity. [143-145] While the Social Ecological Model was used to guide this project, the policy and organizational levels were not included. Therefore factors at both of these levels should be explored in combination with gender, parent BMI, family composition, SES, and 
rurality for their influence on child physical activity and parent support for child physical activity. At the organizational or school level, factors such as school physical activity equipment, parent programs, and extracurricular opportunities could all influence parent support for child physical activity and could potentially interact with child gender and rurality. There could be increased extracurricular opportunities for boys, enabling parents of boys to have higher levels of support. At the policy level, educational funding and physical education and recess requirements should be examined to determine if there are interactions with rurality, gender, and SES that are influencing support for child physical activity. Additionally within the three levels measured, individual, interpersonal, and community, this project did not conduct a comprehensive assessment of all influences. Therefore at any level there could be additional research on factors that may influence parental support for child physical activity. Further, we did not conduct analysis across levels to see how factors from different levels interact. Finally, while we are measuring rural and urban areas, it should be noted that the entire sample is from central Appalachia, which could make the entire sample rural by some definitions. Since this was de-identified secondary data utilizing multiple years of data, there is a chance that some of the parents were surveyed twice. Their answers, however, would have been about different children.

Finally, the study in chapter 2 utilized questions from the YRBS, an adolescent survey, to assess physical activity in parents. [109] These questions are similar to the adult questionnaire however and differ only in time increments. [106] In chapter 3, the study exploring family structure would have benefited from a larger sample of fathers to determine the influence of parent gender on parent support for physical activity. 


\subsection{Future Research}

Future research should assess influences on parental support for child physical activity from the policy and school levels of the Social Ecological Model. This will provide a greater picture overall of influences on parental support. Additionally, within each level examined in this project there are other aspects that should also be explored in addition to researching interactions that occur across multiple levels of the Social Ecological Model. For example, as more information is gathered, it will be important to develop a conceptualized model of all influences on parental support for child physical activity, and their interactions, and then to analyze data through multi-level modeling. At the individual level, which is discussed in Chapter 2, the influence of parent health outcomes should be examined. While this study reviewed health risk behavior, it did not assess chronic disease specifically. It could be that parents with chronic disease would be less able to support child physical activity due to less time due to seeking medical treatment or due to decreased energy as a result of being ill. Therefore, future studies should examine the influence of chronic disease on parent support for physical activity. Additionally the finding that grade was a significant predictor of support for physical activity in parents of girls leads to additional questions about the role of maturation and decreases in physical activity in girls. Future research should determine if increasing parental support for activity is a successful mechanism to target declines in physical activity in all girls, and specifically in those who mature early. At the interpersonal level, future studies should examine the influence of parent gender. While parents of girls appeared have more significant influences on parental support, there could be a parent gender effect since the majority of parents were mothers. The finding that girls with more siblings received higher levels of parent support for physical activity suggests a need for further research on girls without siblings and, perhaps, 
the development of a targeted intervention to increase parent support for physical activity in girls without siblings. Obtaining a larger sample in future studies could also enable researchers to examine the effect of birth order. Additionally, the finding in Chapter 3 that families with higher SES resulted in lower levels of parental support in parents of girls leads to multiple research questions about the role available resources, including parent time, and overcoming barriers in regards to supporting boys' and girls' physical activity. It also calls for the use of a more specific measure of SES including measures of parent education and employment. Perhaps it is easier for families to support or provide physical activity opportunities for boys due the presence of greater opportunities for boys in the community. For example, there may be more opportunity for team sports and programs for boys. It will be important to determine whether boys' physical activity is seen as a greater priority by parents and how parent support is influenced by the community in which they live. A larger, multi-state sample could also enable future research to examine minor influences of rurality on parent support for physical activity. Finally, including more grades in similar research could provide additional information on how parent support decreases as children grow.

\subsection{Conclusion}

This project examined the influence of factors at three levels of the Social Ecological Model on parental supportive behavior for child physical activity. Overall, parents of boys reported higher levels of support for physical activity than did parents of girls. At the individual level, we found that with parents of girls, but not with parents of boys, support for physical activity was positively associated with parent BMI. This finding leads to additional research questions about the role of parent gender and the relationship between mothers and daughters regarding physical activity, nutrition and obesity prevention. At the interpersonal level, an 
examination of family structure revealed that total number of children in the home was a positive predictor of parent support for physical activity in parents of girls, but not in parents of boys, and that SES was a negative predictor in parents of girls, but not in parents of boys. This also leads to additional questions about the role of socioeconomic factors such as parent employment and how these factors impact support for physical activity in boys and girls. Finally, at the community level, no significant differences were found between parents in rural and non rural communities. While not significant, rural parents did report higher levels of support. Future research should examine a larger more representative sample to explore influences of age, parent gender, and rurality more in depth. While this project certainly has limitations, it does seem apparent that girls do receive lower levels of support for physical activity and parents of girls have more significant influences on supportive behavior for child physical activity than do parents of boys. 


\section{Appendix A: Rural-Urban Commuting Area Codes (RUCAs)}

\section{RUCA Data}

\section{Code Definitions: Version 2.0}

1 Metropolitan area core: primary flow within an Urbanized Area (UA)

1.1 Secondary flow $30 \%$ through $49 \%$ to a larger UA

2 Metropolitan area high commuting: primary flow $30 \%$ or more to a UA

2.1 Secondary flow $30 \%$ through $49 \%$ to a larger UA

3 Metropolitan area low commuting: primary flow $10 \%$ to $30 \%$ to a UA

4 Micropolitan* area core: primary flow within an Urban Cluster of 10,000 through 49,999 (large UC)

4.1 Secondary flow $30 \%$ through $49 \%$ to a UA

4.2 Secondary flow $10 \%$ through $29 \%$ to a UA

5 Micropolitan* high commuting: primary flow $30 \%$ or more to a large UC

5.1 Secondary flow $30 \%$ through $49 \%$ to a UA

5.2 Secondary flow $10 \%$ through $29 \%$ to a UA

6 Micropolitan* low commuting: primary flow $10 \%$ to $30 \%$ to a large UC

6.1 Secondary flow $10 \%$ through $29 \%$ to a UA

$7 \quad$ Small town core: primary flow within an Urban Cluster of 2,500 through 9,999 (small UC)

7.1 Secondary flow $30 \%$ through $49 \%$ to a UA

7.2 Secondary flow $30 \%$ through $49 \%$ to a large UC

7.3 Secondary flow $10 \%$ through $29 \%$ to a UA

7.4 Secondary flow $10 \%$ through $29 \%$ to a large UC

8 Small town high commuting: primary flow $30 \%$ or more to a small UC

8.1 Secondary flow $30 \%$ through $49 \%$ to a UA

8.2 Secondary flow $30 \%$ through $49 \%$ to a large UC 
8.3 Secondary flow $10 \%$ through $29 \%$ to a UA

8.4 Secondary flow $10 \%$ through $29 \%$ to a large UC

9 Small town low commuting: primary flow $10 \%$ through $29 \%$ to a small UC

9.1 Secondary flow $10 \%$ through $29 \%$ to a UA

9.2 Secondary flow $10 \%$ through $29 \%$ to a large UC

10 Rural areas: primary flow to a tract outside a UA or UC (including self)

10.1 Secondary flow $30 \%$ through $49 \%$ to a UA

10.2 Secondary flow $30 \%$ through $49 \%$ to a large UC

10.3 Secondary flow $30 \%$ through $49 \%$ to a small UC

10.4 Secondary flow $10 \%$ through $29 \%$ to a UA

10.5 Secondary flow $10 \%$ through $29 \%$ to a large UC

10.6 Secondary flow $10 \%$ through $29 \%$ to a small UC

\section{UA=Urbanized Area}

\section{UC $=$ Urban Cluster}

RUCA Four Group Division

The most common use of RUCA codes is to divide them into the following four aggregate groups. For three groups is it recommended to combine the two middle groups and for a dichotomous measure to combine the bottom three groups into a 'rural' category.

Urban focused: $1.0,1.1,2.0,2.1,3.0,4.1,5.1,7.1,8.1$, and 10.1 .

Large rural/town (micropolitan) focused: 4.0, 4.2, 5.0, 5.2, 6.0, and 6.1

Small rural town focused: 7.0, 7.2, 7.3, 7.4, 8.0, 8.2, 8.3, 8.4, 9.0, 9.1, 9.2

Isolated Small Rural Town focused: 10.0, 10.2, 10.3, 10.4, 10.5, and 10.6 


\section{Parent Survey Questions}

\section{Appendix B: Survey Questions}

5. Does your child participate in the free or reduced lunch program?

Yes

No

20. Please indicate HOW OFTEN you:

A. Encourage your child to be physically active

B. Transport your child to a place to be physically active

E. Praise your child for being physically active

H. Take part in physical activity with your child

S. Watch your child play sports or be physically active

Never/Almost Never

Monthly

Weekly

Almost Daily

Daily

How many servings of fruits and/or vegetables do YOU eat every day?

40. During the past 30 days, on the days that you smoked, how many cigarettes did you smoke per day?

I did not smoke cigarettes during the past 30 days

Less than 1 cigarette per day

1 cigarette per day

2 to 5 cigarettes per day

6 to 10 cigarettes per day

11 to 20 cigarettes per day

More than 20 cigarettes per day

41. What is your: Height: feet inches

Weight: Pounds 
46. On how many of the past 7 days did YOU exercise or participate in physical activities for at least $\mathbf{2 0}$ minutes that made you sweat and breathe hard, such as basketball, soccer, running, swimming, laps, fast bicycling, fast dancing, or similar aerobic activities?

0 days 1 day $\quad 2$ days $\quad 3$ days $\quad 4$ days $\quad 5$ days 6 days 7 days

47. On how many of the past 7 days did YOU participate in physical activity for at least 30 minutes that did NOT make you sweat or breathe hard, such as fast walking, slow bicycling, skating, pushing a lawn mower, or mopping floors?

0 days 1 day $\quad 2$ days $\quad 3$ days 4 days $\quad 5$ days 6 days 7 days

What are the ages of children (18 and under) in your household:

Female's Age

Male's Age

\begin{tabular}{|l|c|l|}
\hline & First Child & \\
\hline & Second Child & \\
\hline & Third Child & \\
\hline & Fourth Child & \\
\hline & Fifth Child & \\
\hline & Sixth Child & \\
\hline & Seventh Child & \\
\hline & Eighth Child & \\
\hline
\end{tabular}

51. How many adults 19 and over live are in your household: (including yourself)

Screening Data:

Gender

Zip code 
References 


\section{References}

1. Ogden, CL et al. Prevalence of overweight and obesity in the United States, 1999-2004. JAMA: The Journal Of The American Medical Association, 2006. 295(13): p. 1549-55.

2. Isganaitis, E \& Levitsky, LL. Preventing childhood obesity: can we do it? Current Opinion In Endocrinology, Diabetes, And Obesity, 2008. 15(1): p. 1-8.

3. Barlow, SE. Expert committee recommendations regarding the prevention, assessment, and treatment of child and adolescent overweight and obesity: summary report. Pediatrics, 2007. 120 Suppl 4: p. S164-92.

4. IOM. Preventing Childhood Obesity: Health in the Balance, ed. J. Koplan, Liverman, CT, Kraak, VI. 2005, Washington, DC: National Academies Press.

5. IOM. Progress in preventing childhood obesity: How do we measure up? , J. Koplan, Liverman, CT, Kraak, VI, \& Wisham, SL, Editor. 2007, National Academies Press: Washington DC.

6. Sherry, B. Food behaviors and other strategies to prevent and treat pediatric overweight. International Journal of Obesity, 2005. 29: p. S116-S126.

7. Owen, N. et al., Too much sitting: the population health science of sedentary behavior. Exerc Sport Sci Rev, 2010. 38: p. 105-113.

8. Pate, R, O'Neill, J, \& Lobelo, F. The evolving definition of 'sedentary'. Exerc Sport Sci Rev, 2008. 36: p. 173-178.

9. Chinapaw, MJM, et al. Relationship between young peoples' sedentary behaviour and biomedical health indicators: a systematic review of prospective studies. Obesity Reviews. 12(7): p. e621-e632.

10. Horn, $\mathrm{O}$, et al. Correlates and predictors of adiposity among Mohawk children. Prev Med, 2001. 33: p. 274-281.

11. Delmas, C, et al. Association between television in bedroom and adiposity throughout adolescence. Obesity (Silver Spring), 2007. 15: p. 2495-2503.

12. Freedman, DS, et al. The relation of childhood BMI to adult adiposity: the Bogalusa Heart Study. Pediatrics, 2005. 115(1): p. 22-7.

13. Singh, AS, et al. Tracking of childhood overweight into adulthood: a systematic review of the literature. Obesity Reviews: An Official Journal Of The International Association For The Study Of Obesity, 2008. 9(5): p. 474-88.

14. Salvadori, M, et al. Elevated blood pressure in relation to overweight and obesity among children in a rural Canadian community. Pediatrics, 2008. 122(4): p. e821-7.

15. Dietz, WH. Childhood weight affects adult morbidity and mortality. The Journal Of Nutrition, 1998. 128(2 Suppl): p. 411S-414S.

16. Freedman, DS, et al. Cardiovascular risk factors and excess adiposity among overweight children and adolescents: the Bogalusa Heart Study. The Journal Of Pediatrics, 2007. 150(1): p. 12-17 e2.

17. Dietz, WH. Health consequences of obesity in youth: childhood predictors of adult disease. Pediatrics, 1998. 101(3 Pt 2): p. 518-25.

18. Pate, RR, et al. Associations between physical activity and other health behaviors in a representative sample of US adolescents. American Journal Of Public Health, 1996. 86(11): p. 1577-81. 
19. Biddle, SJ, Gorely, T, \& Stensel, DJ. Health-enhancing physical activity and sedentary behaviour in children and adolescents. J Sports Sci, 2004. 22(8): p. 679-701.

20. Floriani, V \& Kennedy, C. Promotion of physical activity in children. Curr Opin Pediatr, 2008. 20(1): p. 90-5.

21. Metcalf, BS, et al. Physical activity at the government-recommended level and obesityrelated health outcomes: a longitudinal study (Early Bird 37). Archives Of Disease In Childhood, 2008. 93(9): p. 772-7.

22. McGavock, J, Sellers, E, \& Dean, H. Physical activity for the prevention and management of youth-onset type 2 diabetes mellitus: focus on cardiovascular complications. Diab Vasc Dis Res, 2007. 4(4): p. 305-10.

23. Hallal, PC, et al. Adolescent physical activity and health: a systematic review. Sports Med, 2006. 36(12): p. 1019-30.

24. Kirkcaldy, BD, Shephard, RJ, \& Siefen, RG. The relationship between physical activity and self-image and problem behaviour among adolescents. Soc Psychiatry Psychiatr Epidemiol, 2002. 37(11): p. 544-50.

25. Stein, $\mathrm{C}$, et al. Adolescent physical activity and perceived competence: does change in activity level impact self-perception? J Adolesc Health, 2007. 40(5): p. 462 e1-8.

26. Iannotti, R, et al. Interrelationships of adolescent physical activity, screen-based sedentary behaviour, and social and psychological health. Int J Public Health, 2009. 54 : p. S191-S198.

27. Crews, DJ, Lochbaum, MR, \& Landers, DM. Aerobic physical activity effects on psychological well-being in low-income Hispanic children. Percept Mot Skills, 2004. 98(1): p. 319-24.

28. Trost, S. Active education: Physical education, physical activity and academic performance, in Active Living Research. 2007, The Robert Wood Johnson Foundation.

29. Wittberg, R, Northrup, K, \& Cottrell, L. Children's physical fitness and academic performance. American Journal of Health Education, 2009. 40: p. 30-36.

30. WVDEOHS. Physical Education in WV Schools. [cited 2010 March 24]; Available from: http://wvde.state.wv.us/osshp/section6/PhysicalEducationNew.html\#Fitnessgram.

31. WVDE. WESTEST 2 OVERVIEW. [cited 2010 March 24]; Available from: http://wvde.state.wv.us/oaa/westest_index.html.

32. Strong, WB, et al. Evidence based physical activity for school-age youth. The Journal Of Pediatrics, 2005. 146(6): p. 732-7.

33. CDC. Center for Diesease Control and Prevention. Trends in the Prevalence of Physical Activity. National YRBS: 1991-2007. 2007; Available from:

http://www.cdc.gov/HealthyYouth/yrbs/pdf/yrbs07_us_physical_activity_trend.pdf.

34. Caspersen, CJ, Pereira, MA \& Curran, KM. Changes in physical activity patterns in the United States, by sex and cross-sectional age. Medicine And Science In Sports And Exercise, 2000. 32(9): p. 1601-9.

35. Trost, SG, et al. Age and gender differences in objectively measured physical activity in youth. Medicine And Science In Sports And Exercise, 2002. 34(2): p. 350-5.

36. Kimm, SY, et al. Decline in physical activity in black girls and white girls during adolescence. The New England Journal Of Medicine, 2002. 347(10): p. 709-15.

37. Kimm, SY, et al. Relation between the changes in physical activity and body-mass index during adolescence: a multicentre longitudinal study. Lancet, 2005. 366(9482): p. 301-7. 
38. Shakib, S. Female basketball participation: Negotiating the conflation of peer status and gender status from childhood through puberty. The American Behavioral Scientist, 2003. 46(10): p. 18.

39. Elder, JP, et al. A description of the social-ecological framework used in the trial of activity for adolescent girls (TAAG). Health Educ Res, 2007. 22(2): p. 155-65.

40. Lips, HM. Sex and gender. 6 ed. 2008, New York: McGraw-Hill Higher Education.

41. Rathus, SA, Nevid, JS \& Fichner-Rathus, L. Human sexuality. 2002, Allyn \& Bacon: Boston. p. 186.

42. Blakemore, J, Berenbaum, S, \& Liben, L. Gender development. 2009, New York, NY: Psychology Press.

43. Bandura, A. Social learning theory. 1977, Englewood Cliffs, NJ: Prentice-Hall.

44. Money, J. The concept of gender identity disorder in childhood and adolescence after 39 years. Journal of Sex \& Marital Therapy, 1994. 20(3): p. 163-177.

45. Kyratzis, A, Marx, T, \& Wade, ER. Preschoolers' communicative competence: Register shift in the marking of power in different contexts of friendship group talk. First Language, 2001. 21(63,Pt3): p. 387-431.

46. Giuliano, TA \& Popp, KE. Footballs versus barbies: Childhood play activities as predictors of sport participation by women. Sex Roles, 2000. 42(3/4): p. 159-181.

47. Greendorfer, SL. Gender bias in the theoretical perspectives. Psychology of Women Quarterly, 1987. 11(3): p. 327.

48. Sweeney, J. \& Bradbard, MR. Mothers' and fathers' changing perceptions of their male and female infants over the course of pregnancy. Journal of Genetic Psychology, 1988. 149(3): p. 393.

49. Mondschein, ER, Adolph, KE, \& Tamis-LeMonda, CS. Gender bias in mothers' expectations about infant crawling. Journal of Experimental Child Psychology, 2000. 77(4): p. 304-316.

50. Bunker, L. Physical Activity \& Sport in the Lives of Girls. 1997, The President's Council on Physical Fitness and Sports.

51. Coakley, J, \& White, A. Making decisions: Gender and sport participation among british adolescents. Sociology of Sport Journal, 1992. 9(1): p. 20-35.

52. Lewko, JH, \& Ewing, ME. Sex differences and parental influence in sport involvement of children. Journal of Sport Psychology, 1980. 2(1): p. 62-68.

53. Olvera, N, et al. BOUNCE: an exploratory healthy lifestyle summer intervention for girls. Am J Health Behav, 2010. 34(2): p. 144-55.

54. Stevens, J, et al. Design of the trial of activity in adolescent girls (TAAG). Contemp Clin Trials, 2005. 26(2): p. 223-33.

55. Sallis, JF, Taylor, WC, Dowda, M, Freedson, PS, \& Pate, RR. Correlates of vigorous physical activity for children in grades 1 through 12: Comparing parent-reported and objectively measured physical activity. Pediatric Exercise Science, 2002. 14: p. 30-44.

56. Dollman, J, Norton, K, \& Norton, L. Evidence for secular trends in children's physical activity behaviour. Br J Sports Med, 2005. 39(12): p. 892-7; discussion 897.

57. Ferreira, I, et al. Environmental correlates of physical activity in youth - a review and update. Obes Rev, 2007. 8(2): p. 129-54.

58. Sallis, JF, Prochaska, JJ, \& Taylor, WC. A review of correlates of physical activity of children and adolescents. Medicine And Science In Sports And Exercise, 2000. 32(5): p. 963-75. 
59. Yousefian, A, et al. Active living for rural youth: addressing physical inactivity in rural communities. J Public Health Manag Pract, 2009. 15(3): p. 223-31.

60. Felton, GM, et al. Differences in physical activity between black and white girls living in rural and urban areas. J Sch Health, 2002. 72(6): p. 250-5.

61. Loucaides, CA, Plotnikoff, RC, \& Bercovitz, K. Differences in the correlates of physical activity between urban and rural Canadian youth. J Sch Health, 2007. 77(4): p. 164-70.

62. Joens-Matre, RR, et al. Rural-urban differences in physical activity, physical fitness, and overweight prevalence of children. J Rural Health, 2008. 24(1): p. 49-54.

63. Treuth, MS, et al. Accelerometry-measured activity or sedentary time and overweight in rural boys and girls. Obesity Research, 2005. 13(9): p. 1606-14.

64. Gustafson, SL \& Rhodes, RE. Parental correlates of physical activity in children and early adolescents. Sports Med, 2006. 36(1): p. 79-97.

65. Anderssen, N, \& Wold, B. Parental and peer influences on leisure-time physical activity in young adolescents. Res Q Exerc Sport, 1992. 63(4): p. 341-8.

66. Sallis, JF, et al. Parental behavior in relation to physical activity and fitness in 9-year-old children. Am J Dis Child, 1992. 146(11): p. 1383-8.

67. Beets, MW, et al. Social support and youth physical activity: the role of provider and type. American Journal Of Health Behavior, 2006. 30(3): p. 278-89.

68. Sallis, JF, et al. Predictors of change in children's physical activity over 20 months. Variations by gender and level of adiposity. Am J Prev Med, 1999. 16(3): p. 222-9.

69. Biddle, S, \& Goudas, M. Analysis of children's physical activity and its association with adult encouragement and social cognitive variables. J Sch Health, 1996. 66(2): p. 75-8.

70. DiLorenzo, TM, et al. Determinants of exercise among children. II. A longitudinal analysis. Prev Med, 1998. 27(3): p. 470-7.

71. Davison, KK, Cutting, TM, \& Birch, LL. Parents' activity-related parenting practices predict girls' physical activity. Med Sci Sports Exerc, 2003. 35(9): p. 1589-95.

72. Cardon, G, et al. Physical activity levels in 10- to 11-year-olds: clustering of psychosocial correlates. Public Health Nutrition, 2005. 8(7): p. 896-903.

73. Kuo, J, et al. Associations between family support, family intimacy, and neighborhood violence and physical activity in urban adolescent girls. Am J Public Health, 2007. 97(1): p. 101-3.

74. Beets, MW, Pitetti, KH, \& Forlaw, L. The role of self-efficacy and referent specific social support in promoting rural adolescent girls' physical activity. American Journal Of Health Behavior, 2007. 31(3): p. 227-37.

75. Bjorklund, D, \& Blasi, C. Child and adolescent development: An integrated approach. 2011, Wadsworth Publishing: Belmont, CA.

76. Dowda, M, et al. Family support for physical activity in girls from 8 th to 12 th grade in South Carolina. Prev Med, 2007. 44(2): p. 153-9.

77. We Can! Progress report: Curriculum implementation by intensive sites. 2007.

78. McLeroy, KR, et al. An ecological perspective on health promotion programs. Health Educ Q, 1988. 15(4): p. 351-77.

79. Patterson, PD, et al. Obesity and physical inactivity in rural America. J Rural Health, 2004. 20(2): p. 151-9.

80. Reis, JP, et al. Nonoccupational physical activity by degree of urbanization and U.S. geographic region. Med Sci Sports Exerc, 2004. 36(12): p. 2093-8. 
81. Singh, GK, Kogan, MD, van Dyck, PC. A multilevel analysis of state and regional disparities in childhood and adolescent obesity in the United States. J Community Health, 2008. 33(2): p. 90-102.

82. Sallis, JF \& Owen, N. Ecological models of health behavior, in Health behavior and health education. Theory, Research, and Practice, K. Glanz, B. Rimer, and F. Lewis, Editors. 2002, Jossey-Bass: San Francisco, CA.

83. Trost, SG, et al. Evaluating a model of parental influence on youth physical activity. American Journal Of Preventive Medicine, 2003. 25(4): p. 277-82.

84. Pugliese, J. \& Tinsley, B. Parental socialization of child and adolescent physical activity: a meta-analysis. Journal Of Family Psychology: JFP: Journal Of The Division Of Family Psychology Of The American Psychological Association (Division 43), 2007. 21(3): p. 331-43.

85. Richards, R, et al. Childhood and contemporaneous correlates of adolescent leisure time physical inactivity: a longitudinal study. J Adolesc Health, 2009. 44(3): p. 260-7.

86. Bagley, S, Salmon, J, \& Crawford, D. Family structure and children's television viewing and physical activity. Medicine And Science In Sports And Exercise, 2006. 38(5): p. 9108.

87. Gorely, T, et al. Family circumstance, sedentary behaviour and physical activity in adolescents living in England: Project STIL. International Journal of Behavioral Nutrition and Physical Activity, 2009. 6: p. 8.

88. Dunton, GF, et al. Physical environmental correlates of childhood obesity: a systematic review. Obes Rev, 2009. 10(4): p. 393-402.

89. Grunbaum, JA, et al. Youth Risk Behavior Surveillance -- United States, 2003. MMWR: Morbidity \& Mortality Weekly Report, 2004. 53(SS-2): p. 1-95.

90. Prochaska, JJ, Rodgers, MW, \& Sallis, JF. Association of parent and peer support with adolescent physical activity. Research Quarterly For Exercise And Sport, 2002. 73(2): p. 206-10.

91. Rondon, MB, A gender perspective is fundamental to improve women's health. Journal of Women's Health (15409996). 19(11): p. 1949-1950.

92. Ezzati, M \& Lopez, AD. Estimates of global mortality attributable to smoking in 2000. Lancet, 2003. 362(9387): p. 847-852.

93. Jia, H \& Lubetkin, EI. Obesity-Related Quality-Adjusted Life Years Lost in the U.S. from 1993 to 2008. American Journal of Preventive Medicine, 2010. 39(3): p. 220-227.

94. Fogelholm, M, et al. Parent-child relationship of physical activity patterns and obesity. Int J Obes Relat Metab Disord, 1999. 23(12): p. 1262-8.

95. Lin, BH, Huang, CL, \& French, SA. Factors associated with women's and children's body mass indices by income status. Int J Obes Relat Metab Disord, 2004. 28(4): p. 53642.

96. Danielzik, S, et al. Parental overweight, socioeconomic status and high birth weight are the major determinants of overweight and obesity in 5-7 y-old children: baseline data of the Kiel Obesity Prevention Study (KOPS). International Journal of Obesity \& Related Metabolic Disorders, 2004. 28(11): p. 1494-1502.

97. Levi, J, Vinter, S, Richardson, L, St. Laurent, R, \& Segal, LM. F as in fat: How obesity policies are failing in America: Trust for America's Health. 2009. 
98. von Kries, RD, et al. Parental smoking and childhood obesity--is maternal smoking in pregnancy the critical exposure? International Journal Of Epidemiology, 2008. 37(1): p. 210-216.

99. Barnoya, J \& Glantz, SA. Cardiovascular Effects of Secondhand Smoke: Nearly as Large as Smoking. Circulation, 2005. 111(20): p. 2684-2698.

100. Epstein, LH, et al. Determinants of physical activity in obese children assessed by accelerometer and self-report. Medicine And Science In Sports And Exercise, 1996. 28(9): p. 1157-1164.

101. CDC. West Virginia: Burden of chronic diseases. 2008 [cited 2011 June 10, 2011]; Available from: http://www.cdc.gov/chronicdisease/states/pdf/west_virginia.pdf.

102. Cottrell, LA, et al. Comparisons of parent cardiovascular knowledge, attitudes, and behaviors based on screening and perceived child risks. J Community Health Nurs, 2007. 24(2): p. 87-99.

103. Demerath, E, et al. School-based obesity screening in rural Appalachia. Prev Med, 2003. 37(6 Pt 1): p. 553-60.

104. Harris, CV \& Neal, WA. Assessing BMI in West Virginia schools: parent perspectives and the influence of context. Pediatrics, 2009. 124 Suppl 1: p. S63-72.

105. Ice, CL, Cottrell, L, \& Neal, WA. Body mass index as a surrogate measure of cardiovascular risk factor clustering in fifth-grade children: results from the coronary artery risk detection in the Appalachian Communities Project. Int J Pediatr Obes, 2009. 4(4): p. 316-24.

106. CDC. Behavioral Risk Factor Surveillance System. [cited 2010 April 1]; Available from: http://www.cdc.gov/brfss/.

107. Ling, PM, Neilands, TB, \& Glantz, SA. Young adult smoking behavior: A national survey. American Journal of Preventive Medicine, 2009. 36(5): p. 389-394.

108. Wechsler, $\mathrm{H}$, et al. Increased levels of cigarette use among college students. JAMA: Journal of the American Medical Association, 1998. 280(19): p. 1673.

109. CDC. YRBSS: Youth Risk Behavior Surveillance System. Available from: http://www.cdc.gov/HealthyYouth/yrbs/index.htm.

110. Physical Activity Guidelines Advisory Committee Report 2008, U.S. Department of Health and Human Services: Washington, DC.

111. Eisenmann, JC, et al. Combined influence of physical activity and television viewing on the risk of overweight in US youth. International Journal Of Obesity (2005), 2008. 32(4): p. 613-618.

112. Nelson, DE, et al. Reliability and validity of measures from the Behavioral Risk Factor Surveillance System (BRFSS). Sozial- Und PrÃăventivmedizin, 2001. 46 Suppl 1: p. S3S42.

113. Cappuccio, FP, et al. Estimation of fruit and vegetable intake using a two-item dietary questionnaire: a potential tool for primary health care workers. Nutrition, Metabolism, And Cardiovascular Diseases: NMCD, 2003. 13(1): p. 12-19.

114. Rushovich, BR, et al. The relationship between unsupervised time after school and physical activity in adolescent girls. The International Journal Of Behavioral Nutrition And Physical Activity, 2006. 3: p. 20-20.

115. WVBOE. Free and Reduced Price School Meals Family Application. W.V.B.o. Education. 2009. 
116. Tabachnick, B \& Fidell, L. Using Multivariate Statistics. 2007, Boston: Pearson Education, Inc.

117. Francis, LA, Hofer, SM, \& Birch, LL. Predictors of maternal child-feeding style: maternal and child characteristics. Appetite, 2001. 37(3): p. 231-243.

118. Baker, BL, et al. Advanced pubertal status at age 11 and lower physical activity in adolescent girls. The Journal Of Pediatrics, 2007. 151(5): p. 488-493.

119. Davison, KK, et al. Why are early maturing girls less active? Links between pubertal development, psychological well-being, and physical activity among girls at ages 11 and 13. Social Science \& Medicine (1982), 2007. 64(12): p. 2391-404.

120. Census. West Virginia Fact Sheet. 2010 [cited 2011 June 10, 2011]; Available from: http://www.census.gov/.

121. Lemon, SC, et al. Contributions of weight perceptions to weight loss attempts: differences by body mass index and gender. Body Image, 2009. 6(2): p. 90-96.

122. Criqui, MH, Barrett-Connor, E, \& Austin, M. Differences between respondents and nonrespondents in a population-based cardiovascular disease study. American Journal Of Epidemiology, 1978. 108(5): p. 367-372.

123. Fowler, F. Survey research methods. 4th ed. 2009, Thousand Oaks, California: SAGE Publications, Inc.

124. Edwards, A. The social desirability variable in personality assessment and research. 1957, New York, NY: Dryden.

125. Ormrod, J. Human Learning. 1999, Upper Saddle River, NJ: Prentice-Hall.

126. Garcia, AW \& Broda, MAN. Gender and developmental differences in exercise beliefs among youth and prediction of their. Journal of School Health, 1995. 65(6): p. 213.

127. Field, A. Discovering statistics using SPSS, ed. D.B. Wright. 2005, Thousand Oaks, CA: SAGE Publications Inc.

128. Pleis, J \& Lethbridge-Cejku, M. Summary Health Statistics for U.S. Adults: National Health Interview Survey, 2006, in Vital and Health Statistics. 2007, National Center for Health Statistics.

129. Hartley, D. Rural health disparities, population health, and rural culture. American Journal of Public Health, 2004. 94(10): p. 1675-1678.

130. Davy, BM, et al. Body weight status, dietary habits, and physical activity levels of middle school-aged children in rural Mississippi. Southern Medical Journal, 2004. 97(6): p. 571577.

131. Paxton, RJ, Estabrooks, PA, \& Dzewaltowski, D. Attraction to physical activity mediates the relationship between perceived competence and physical activity in youth. Research Quarterly For Exercise And Sport, 2004. 75(1): p. 107-111.

132. McMurray, RG, et al. Cardiovascular disease risk factors and obesity of rural and urban elementary school children. The Journal Of Rural Health: Official Journal Of The American Rural Health Association And The National Rural Health Care Association, 1999. 15(4): p. 365-374.

133. McMurray, RG, et al. The influence of physical activity, socioeconomic status, and ethnicity on the weight status of adolescents. Obesity Research, 2000. 8(2): p. 130-139.

134. CDC. Centers for Disease Control and Prevention. Physical activity levels among children aged 9-13 years--United States, 2002. MMWR: Morbidity \& Mortality Weekly Report, 2003. 52(33): p. 785-788. 
135. Lutfiyya, MN, et al. Is rural residency a risk factor for overweight and obesity for U.S. children? Obesity (Silver Spring, Md ), 2007. 15(9): p. 2348-56.

136. Danaher, B, et al. Measuring participant rurality in Web-based interventions. BMC Public Health, 2007. 7(1): p. 228.

137. Rosenblatt, $\mathrm{R}$, et al. Shortages of medical personnel at community health centers: implications for planned expansion. JAMA, 2006. 295: p. 1042 - 1049.

138. WWAMIRHRC. Rural-Urban Community Area Codes (RUCAs). [cited 2010 March 24]; Available from: http://depts.washington.edu/uwruca/index.php.

139. Hart, LG, Larson, EH, \& Lishner, DM. Rural Defnitions for Health Policy and Research. American Journal of Public Health, 2005. 95(7): p. 1149-1155.

140. Garcia, AW, et al. Gender and developmental differences in exercise beliefs among youth, and prediction of their exercise behavior. Kango Kenkyu. The Japanese Journal Of Nursing Research, 1997. 30(3): p. 221-231.

141. USDA. Farms and Land in Farms. 2009, National Agricultural Statistics Service.

142. Hofferth, S, \& Iceland, J. Social capital in rural and urban communities. Rural Sociology, 1998. 63(4): p. 574-598.

143. Jaffee, L, \& Rex, J. Parental encouragement and girls' participation in physical activity. Melpomene, 2000. 19(1): p. 18-23.

144. Raudsepp, L \& Viira, R. Influence of parents' and siblings' physical activity on activity levels of adolescents. European Journal of Physical Education, 2000. 5: p. 169-178.

145. Thompson, VJ, et al. Influences on Diet and Physical Activity among Middle-Class African American 8- to 10-Year-Old Girls at Risk of Becoming Obese. Journal of Nutrition Education \& Behavior, 2003. 35(3): p. 115.

146. Harris, CV, et al. BMI screening in schools - Does an active consent process yield a representative sample of students?, in American Public Health Association. 2009: Philadelphia, PA. 